\title{
Investigation on Friction Stir Weldability Characteristics of AA7075-T651 and AA6061-T6 Based Nanocomposites
}

\author{
M. Madhusudan $\mathbb{D}^{1},{ }^{1}$ S. P. Shanmuganatan $\mathbb{D}^{1},{ }^{1}$ Kurse Shridhar $\mathbb{D}^{2},^{2}$ Jacob John $^{\mathbb{D}}{ }^{1}$ \\ R. Krishnamurthy, ${ }^{3}$ and Bashyam Sasikumar ${ }^{4}$ \\ ${ }^{1}$ Department of Mechanical Engineering, Dayananda Sagar College of Engineering, Bengaluru 560078, India \\ ${ }^{2}$ Department of Automobile Engineering, New Horizon College of Engineering, Bengaluru 560103, India \\ ${ }^{3}$ Department of Manufacturing Engineering, Indian Institute of Technology, Chennai 600032, India \\ ${ }^{4}$ Faculty of Mechanical and Production Engineering, Arba Minch University, Arba Minch, Ethiopia
}

Correspondence should be addressed to Bashyam Sasikumar; bashyam.sasikumar@amu.edu.et

Received 27 October 2021; Accepted 23 November 2021; Published 21 December 2021

Academic Editor: V. Vijayan

Copyright (c) 2021 M. Madhusudan et al. This is an open access article distributed under the Creative Commons Attribution License, which permits unrestricted use, distribution, and reproduction in any medium, provided the original work is properly cited.

\begin{abstract}
Friction stir welding (FSW) is an emerging solid-state process and alternative to fusion welding, wherein frictional heat is generated between a nonconsumable rotating steel tool and the work substrate. The present study focuses on the influence of the operating attributes like tool pin contact geometry, welding speed, and tool rotational speed on dissimilar aluminum matrix nanocomposites. AA6061-T6 and AA7075-T651 aluminum alloy plates were joined via double-pass FSW with the inclusion of 5 vol. \% of nanoscale h-BN particles. Welding was performed with four rotational speeds $(600,800,900$, and $1000 \mathrm{rpm})$, three traversing speeds $(30,40$, and $60 \mathrm{~mm} / \mathrm{min}$ ), and three distinct tool pin geometry (cylindrical, threaded cylindrical, and square), respectively. Besides, unreinforced and reinforced weldments were analyzed for mechanical properties like tensile strength and microhardness. Microstructural characterization was also carried out using FESEM and XRD techniques. The findings concluded that the reinforced samples welded using a cylindrical tool and double-pass strategy showcased homogenous distribution of nanoparticles with grain refinement, thereby exhibiting improved strength and hardness.
\end{abstract}

\section{Introduction}

Friction stir welding (FSW) is a potentially proven solid-state joining method that can overcome the constraints of fusion welding processes. In FSW, a nonconsumable steel tool rotating at high speed is used to generate the frictional heat and stirring over the base metal substrates resulting in a firm weld. The process attributes of FSW operation are tool pin geometry, downward force, tilt angle of the tool, welding speed, and tool rotational speed. FSW is a versatile technology to produce surface composites. The heat treatable and artificially aged aluminum are extensively used in stir welding techniques. The applications of such alloys find suitability in aircraft structures, missile panels, cowls, fuselage, wing skins of the airplane, and so forth. FSW process can also be extended to fabricate aluminum matrix nanocomposites
(AMNCs) finding its wide range of applications in the transportation sector and automotive engine parts.

Dragatogiannis et al. [1] studied FSW (dissimilar) process on 5083 and $6082 \mathrm{Al}$ alloys reinforced with $\mathrm{TiC}$ nanoparticles. The findings concluded that homogeneous distribution of particles and mechanical mixing of the materials result in grain refinement enhancing the mechanical properties compared to unreinforced. Hassan et al. [2] adapted FSW for the fabrication of $\mathrm{SiC}$ and graphite particle reinforced aluminum matrix composites. It was observed that a combination of high welding speeds and low value of rotational speeds improves the wear resistance of the joint associated with dynamic recrystallization of the deformed material.

Cisko et al. [3] performed the parametric investigation to evaluate the rates of tool rotation and feed on the strength 
properties and the microstructure of Al-Li 2099 alloy. The study concluded that tensile strength showcased ascendance with tool traversing speed which furthers the low heat input and minimized the grain growth during FSW. John et al. [4] studied the capability of friction stirring technique concatenated with incremental forming on $3 \mathrm{~mm}$ thick AA 2014-T6 alloy. Multipass stirring was carried out with hexagonal tool pin geometry at the optimized condition of $1000 \mathrm{rpm}$ spindle speed and $60 \mathrm{~mm} / \mathrm{min}$ tool feed which further resulted in the grain refinement with enhanced hardness.

Moharami et al. [5] investigated the (dissimilar) FSW behavior with different tool pins on the mechanical properties and microstructure of AA6061-T6/Al- $\mathrm{Mg}_{2} \mathrm{Si}$ composite. The study revealed that the tapered triangular tool pin was significant in improving the intermaterial flow and reducing the average grain size. The dynamic recrystallization and the particle-pinning effect improved the tensile strength by forming the intermetallic compounds in the weld. Ali et al. [6] characterized the microstructure of aluminum matrix composites with uniform distribution of $\mathrm{SiC}$ and $\mathrm{B}_{4} \mathrm{C}$ particles as the reinforcements arriving at incremental strength along with the refinement of grain. The presence of a reinforcing agent contributes to considerable improvement in the hardness promoting the quality weld.

Abdollahzadeh et al. [7] performed in situ nanocomposite dissimilar Al-Mg friction stir welding. The weld obtained at $650 \mathrm{rpm}$ and $35 \mathrm{~mm} / \mathrm{min}$ revealed $28 \%$ furtherance in tensile strength and augmentation about three times in elongation in contrast to the unreinforced joint. Bahrami et al. [8] fabricated composite joints in two-pass using threaded tapered and square pin tools and concluded that the addition of reinforcement enhanced the tensile strength and elongation property by 7.2 and $137.7 \%$, respectively.

Dinaharan and Murugan [9] studied the effect of stir welding by producing $\mathrm{AA} 6061 / \mathrm{ZrB}_{2}$ in situ cast composites. The study confirmed that the properties like tensile strength, microhardness, and wear resistance were subsequently improved during FSW. Tabasi et al. [10] performed dissimilar friction stir welding using $\mathrm{SiC}$ nanoparticles. An increase in rotational speed and a decrease in feed rate resulted in the proper mixing of two alloys in the nugget zone. The weld microstructure was influenced by the pinning effect. This is in contrast to the results of suggesting lower-order rotating speed and higher feed with the case of $\mathrm{TiC}$ reinforced composites. This could be due to a lowering in the temperature rate since titanium is a reactive element compared to silicon.

Sadooghi and Rahmani [11] employed the multipass FSP technique to produce $\mathrm{Mg}-\mathrm{SiC}$ surface composites and evaluated the material properties. The Groove method was adapted for fixing the reinforcement and to ensure the homogenous distribution of nano/microparticles. Prolonged submission time modified the microstructure during the process contributing to enhanced strength and microhardness of the reinforced specimens in comparison with the base metal. Bodaghi and Dehghani [12] joined AA5052 aluminum sheets by adding $\mathrm{SiC}$ nanoparticles into the weld nugget during FSW, and the stir zone microstructure was enhanced. The mechanical properties were improved with the addition of the nanoparticles.

Singh et al. [13] performed friction stir welding to produce aluminum matrix nanocomposites. Refinement of microstructure in the nugget zone with the inclusion of $\mathrm{TiO}_{2}$ nanoparticles results in the enhancement of mechanical properties. Pandiyarajan et al. [14] produced stir cast hybrid aluminum matrix composites with $\mathrm{ZrO}_{2}$ and graphite reinforcements. The casted composites were welded with varied tool speed, tool feed, and axial force as per the response surface methodology. The researchers highlighted that the study resulted in optimization of process parameters, and also, the microstructure of the composites exhibited the recrystallized fine grains culminating in improved mechanical properties.

It is perceived that there are many research studies pertaining to the FSW process on dissimilar metal alloys like aluminum, magnesium, copper, and others. Ceramic materials like $\mathrm{SiC}, \mathrm{TiC}, \mathrm{B}_{4} \mathrm{C}, \mathrm{Al}_{2} \mathrm{O}_{3}, \mathrm{TiO}_{2}$, and a few more have been used as a reinforcing material at both micron and nanolevel in different proportions to fabricate metal matrix composites by FSW/FSP. The literature studies scrutinizing the morphological studies of FSW on solutionized, artificially aged alloys like AA6061-T6 and AA7075-T651 with the addition of nitride particles as reinforcement and evaluation of mechanical properties on the said composition are, however, limited. Henceforth, the present study converges with the fabrication of AMNC's based on combination of such aluminum alloys subjected to friction stir welding with the inclusion of nanoscale nitride particles and assessment of the composites with different tool pin geometries. The present work embraces a new technique of fixing the nanoparticles in the groove and restraining it from spilling out by coating a thin layer of acetone on the top surface of the groove which further circumvents the fabrication of tool without pin, thereby reducing the welding time.

\section{Materials and Methods}

The commercially available aluminum alloy machined plates, AA6061-T6 (age-hardened and solutionized) and AA7075-T651 (strain hardened) of $100 \mathrm{~mm}$ width, $150 \mathrm{~mm}$ length, and $6.35 \mathrm{~mm}$ thick were chosen as the parent metals for the present study. The chemical elements and mechanical traits of the chosen parent materials are displayed in Tables 1 and 2 .

Hexagonal phase-type boron nitride (h-BN) nanopowder, a refractory compound of about $99.9 \%$ purity and particle size of $50-80 \mathrm{~nm}$, is employed as a reinforcing material for the present work owing to its high hardness, low density, and good lubricity (larger lattice structure) which proves to be a suitable reinforcement particle for aluminum alloys. Figure 1 indicates the SEM and optical macroimage of the nanopowder and its chemical constituents are indexed in Table 3.

A 15 HP capacity and 3-ton experimental setup with a maximum spindle speed of 1450 RPM is employed for the current study and is shown in Figure 2. 
TABLE 1: Chemical constituents of selected base materials.

\begin{tabular}{lcccccccccccc}
\hline Element & $\mathrm{Mg}$ & $\mathrm{Si}$ & $\mathrm{Fe}$ & $\mathrm{Cu}$ & $\mathrm{Cr}$ & $\mathrm{Zn}$ & $\mathrm{Mn}$ & $\mathrm{Ni}$ & $\mathrm{Ti}$ & $\mathrm{Pb}$ & $\mathrm{Sb}$ & $\mathrm{Al}$ \\
\hline AA6061 & 1.03 & 0.66 & 0.570 & 0.253 & 0.242 & 0.137 & 1.105 & 0.03 & 0.02 & 0.02 & 0.05 & 95.8 \\
$\mathrm{AA7075}$ & 2.536 & 0.129 & 0.306 & 1.091 & 0.186 & 6.185 & 0.041 & 0.029 & 0.050 & 0.022 & 0.044 & 89.4 \\
\hline
\end{tabular}

TABle 2: Mechanical properties of chosen base materials.

\begin{tabular}{lcccc}
\hline Materials & UTS $(\mathrm{MPa})$ & YTS $(\mathrm{MPa})$ & Elongation (\%) & Microhardness (Hv) \\
\hline AA6061-T6 & 301.78 & 261.56 & 15.55 & 109.56 \\
AA7075-T651 & 502.56 & 398.43 & 17.25 & 178.32 \\
\hline
\end{tabular}
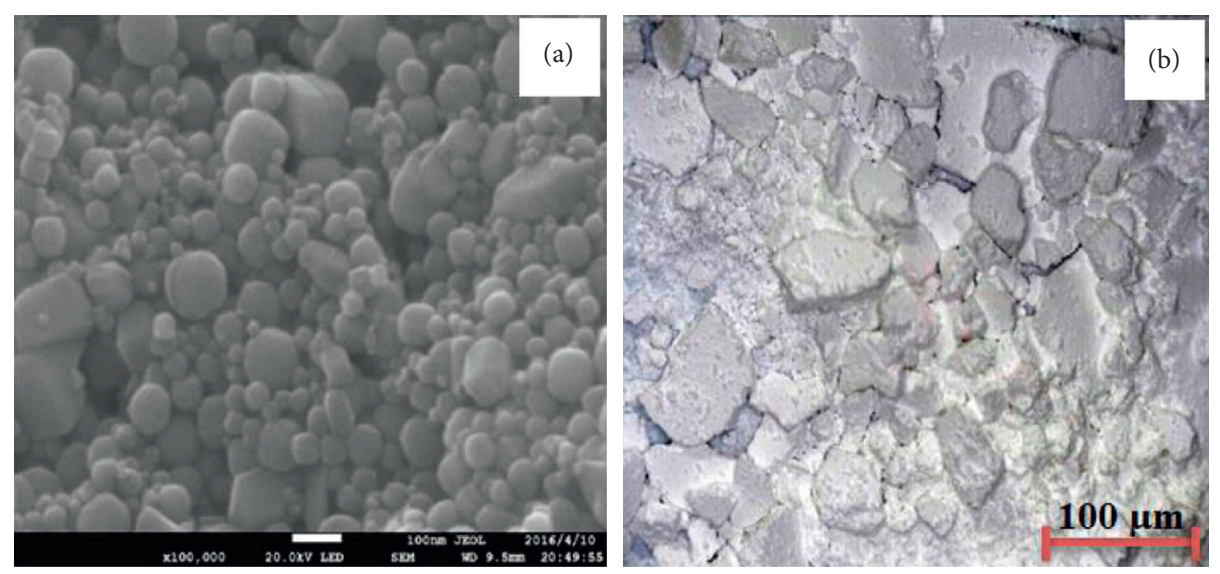

Figure 1: (a) SEM and (b) optical macroimage of h-BN.

TABLE 3: Chemical constituents of reinforcing material.

\begin{tabular}{|c|c|c|c|c|c|c|c|c|c|c|c|c|}
\hline Element & $\mathrm{O}$ & $\mathrm{H}$ & $\mathrm{N}$ & $\mathrm{Pb}$ & $\mathrm{Zn}$ & $\mathrm{Mn}$ & $\mathrm{Si}$ & $\mathrm{Al}$ & $\mathrm{C}$ & $S$ & $\mathrm{Ca}$ & $\mathrm{Fe}$ \\
\hline h-BN & 0.004 & 0.015 & 0.020 & 0.002 & 0.002 & 0.002 & 0.001 & 0.002 & 0.006 & 0.005 & 0.005 & 0.020 \\
\hline
\end{tabular}

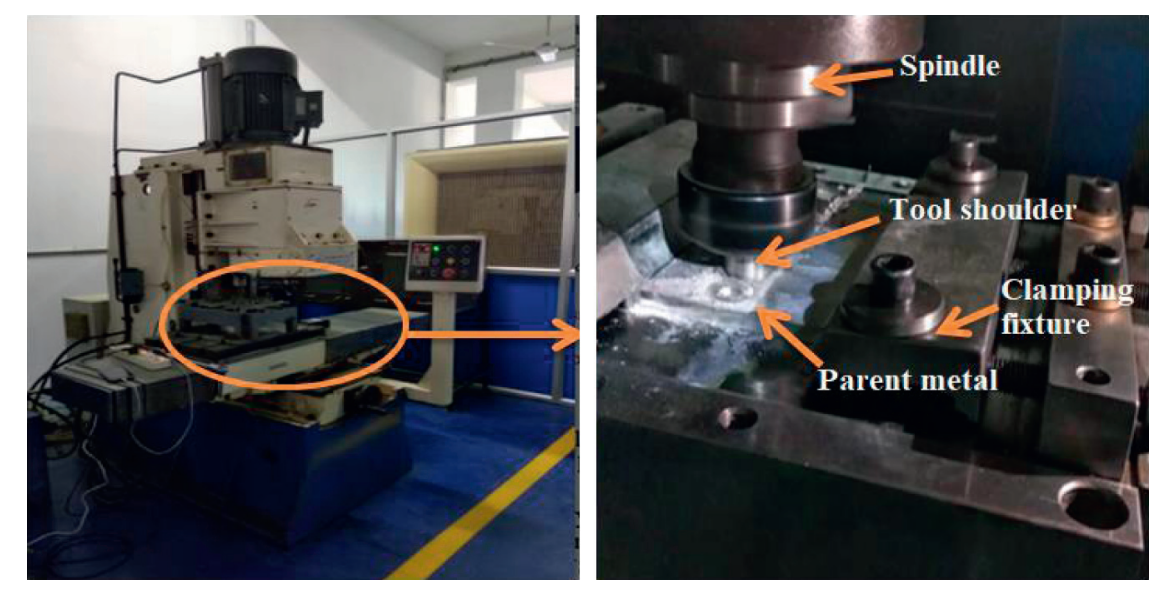

FIgURE 2: FSW experimental setup. 
The method involves the rotation of a cylindrical tool at a higher speed accompanied by plunging action between the butting line of two workpieces. Heat due to friction is developed between the tool pin and base material. The rasping action between the tool shoulder and material generates confined heating expediting the material softening action. The forging/plasticizing action of the material takes place by the swift shoulder-tool pin interaction culminating in transferring/uprooting the material from the forefront to the rear end of the tool (significance of height of the shoulder from the pin bottom). The reverberation of the heat and subsequent mechanical contortion culminates in prominent zones, i.e., heat affected zone (HAZ), thermomechanically treated zone (TMT), and weld nugget zone (WNZ). The schematic depiction of the FSW process is shown in Figure 3.

A tool-work interaction plays a prominent role influenced by spindle speed, traverse feed, and tool pin geometry with subsequent performance over the FSW process [15]. As represented in Figure 4, three distinct tool pin probes, namely, cylindrical, threaded cylindrical, and square, were adapted to obtain homogeneous administering of nanoparticles at the weld nugget zone (WNZ) ensuring the Metal Matrix Nanocomposites [1, 13]. The welding tool material selected for the present study is M-42 high-speed steel (HSS) which is hardened and tempered to $64-66 \mathrm{HRC}$.

Initially, spindle speed of $500-1100 \mathrm{rpm}$, feed of $10-70 \mathrm{~mm} / \mathrm{min}$, and cylindrical pin tool were adapted to perform dissimilar welding without reinforcement. Welding performed at $500 \mathrm{rpm}$ ensued in inadequate/exiguous heat input and weldment staged a surface with poor appearance and distortion besides porosity and cracking. At $1100 \mathrm{rpm}$, rapid flashing of material was noticeable due to excessive heat generation furthering the formation of fine base globular material.

Weldment produced at a feed rate of $10 \mathrm{~mm} / \mathrm{min}$ exhibited disrupted material flow which could be ascribed to augmented residing/dwelling time. As in the case of normal machining, lower feed values would induce a phenomenon similar to the stick slip; i.e., the tool-work interface would encounter material-breaking constraints. At escalated feed rate of $70 \mathrm{~mm} / \mathrm{min}$, porous site formation is triggered attributable to the chaotic flow furtherance to unstable tensile relaxation.

Thereafter, tool rotational speeds ranging from 600 to $1000 \mathrm{rpm}$ and welding speed ranging from 30 to $60 \mathrm{~mm} / \mathrm{min}$ were used for further study. It was also noticed that sound and efficient welding was achieved when the thickness of the plate is $0.5 \mathrm{~mm}$ more than the length of the tool pin and the tool shoulder is 3 times more than the pitch circle diameter of the tool pin. Table 4 depicts the different weld appearances during dissimilar stir welding without reinforcement.

Prior to composite FSW, chosen alloy plates were milled along the edges to maintain the zero-gap, and on one faying surface of each plate, a rectangular groove of length $140 \mathrm{~mm}$ was machined using a CNC milling center to incorporate reinforcing material. All the plates with grooves were carefully degreased with acetone to remove impurities like grease and dirt and then dried in ambient air. The groove was compacted tightly with nanoparticles, and a thin layer of acetone is coated on the top surface of the groove to prevent the particles from spattering. Base alloy AA7075-T651 is positioned along the retreating side (RS), while the AA6061T6 alloy is on the advancing side (AS) to achieve a strong fabricated weld [16]. The welding with double-pass was carried out parallel to the plate rolling direction with 5 vol. \% of reinforcement and axial load of $10 \mathrm{KN}$ for all experimental trial runs.

Inculcating double-pass/multipass strategy during welding improved the quality of weld in terms of strength/ hardness enhancement, which circumvents the uneven distribution of reinforcement particles in the stir zone. The inclusion of nanoparticles in the weld results in a lowerorder frictional coefficient and can be furthered by increasing the number of passes $[8,13]$. Hence, double-pass stir welding involving plunging depth of $0.55 \mathrm{~mm}$ and dwell time of 1 minute (preheating) constitutes the basic experimentation. Table 5 specifies the operating parameters for the proposed welding.

The plasticization effect is significant in friction stir welding contributing to the strength of the joint. To appraise the quality and the strength of stir welds, specimens for the tensile test were machined perpendicular to the weld line using Semi-Automatic Cast Iron CNC EDM Wire Cut DK7745 according to ASTM B557M standard [17]. The tensile test was executed on an MTS (MN USA 55344) universal testing machine. The joint efficiency was also calculated for each weld. The machined tensile specimens before and after testing, standard tensile specimens, and specimens extracted for morphology tests are indicated in Figures 5(a)-5(d).

The microstructure and the particle dispersion in the stir zone were analyzed by optical microscopy (OM) and field emission scanning electron microscopy (FESEM). Standard thermosetting resin mold was used to mount each of the weld samples, polished and etched by Keller's reagent. The specimens were extracted as per ASTM E3-11 standard [18] to reveal the salient traits of structural observation of each specimen. Additionally, elemental spectrum analysis in the nugget region of weld specimens was carried out by energy dispersion spectroscopy (EDS) and X-ray diffraction (XRD). To characterize the microhardness distribution at the distinctive weld zones, Vickers hardness indentation at $0.5 \mathrm{kgf}$ was adopted, and hardness was measured across the interface from the retreating side to the advancing side of each welded composite specimen.

\section{Results and Discussion}

The effects of attributes (tool rotation, 600-1000 rpm, feed rate $30-60 \mathrm{~mm} / \mathrm{min}$, tool pin geometries, CYL, THR CYL, SQ, and constant parameters, 5 vol. \% of reinforcement binder, $10 \mathrm{KN}$ axial load, $0.55 \mathrm{~mm}$ plummet depth, and 1 min dwell) on the mechanical and structural characteristics of h-BN reinforced stir composite were investigated to achieve the working window for firm and sound welds.

Figure 6 illustrates the visual representation of welded composite specimens. A weld obtained with a $40 \mathrm{~mm} / \mathrm{min}$ feed rate and $800 \mathrm{rpm}$ showed small voids at a few locations. The tool 


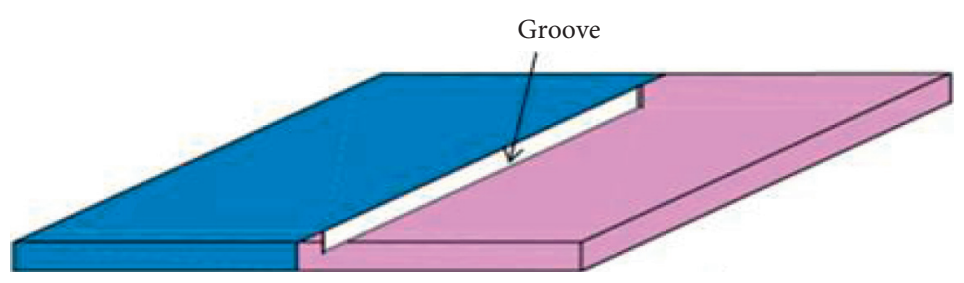

(a)

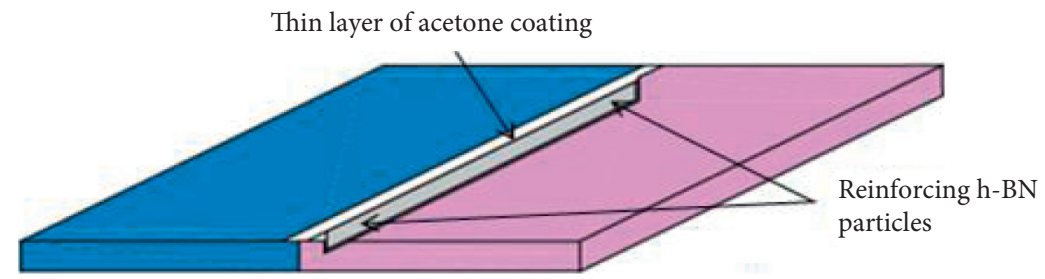

(b)

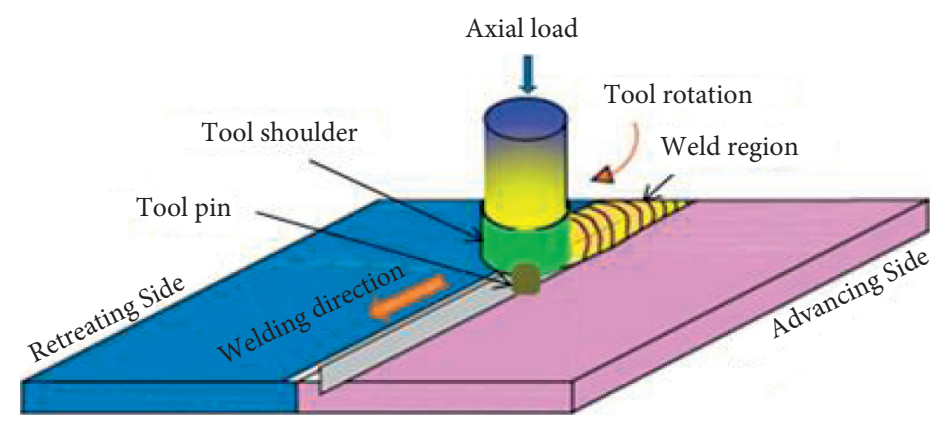

(c)

FIGURE 3: Schematic depiction of FSW process procedure. (a) Groove along the faying surface of the base alloys, (b) compaction of the reinforcing particles, and (c) FSW principle.

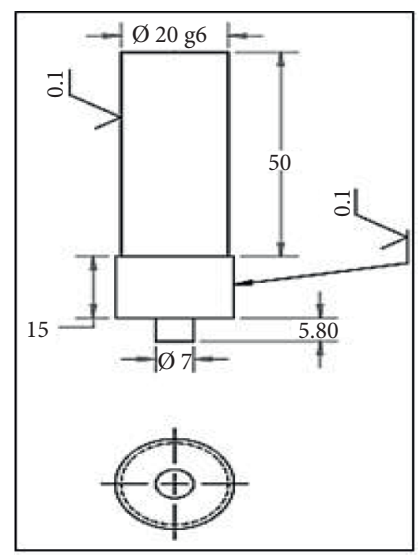

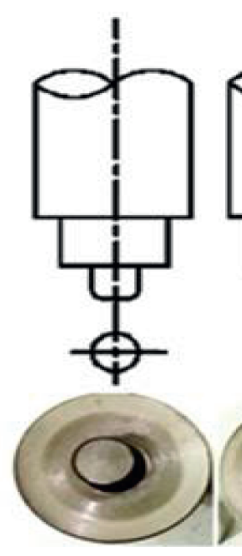

i) CYL

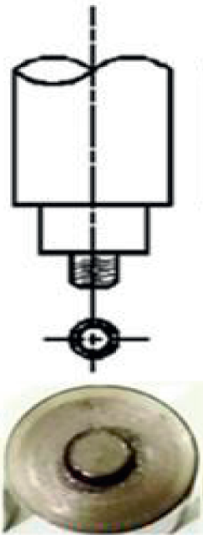

ii) THR CYL

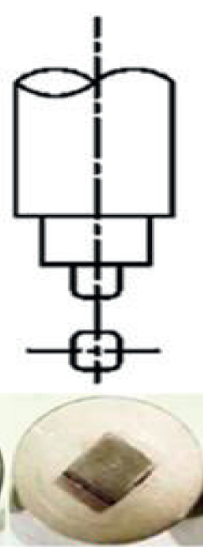

iii) $S Q$

Figure 4: Schematic and photographic views of tool pin probes.

rotation of $900 \mathrm{rpm}$ and welding speed of $30 \mathrm{~mm} / \mathrm{min}$ staged the weldment with an inferior surface finish. A weld operated with a high rotational speed of $1000 \mathrm{rpm}$ with $40 \mathrm{~mm} / \mathrm{min}$ tool feed exhibited a smooth finish on the weld crown. The tool with threaded pin results in a rougher surface, and in the case of the cylindrical tool, visual inspection of the welded joint indicates the relatively smoother; i.e, the better joint formation could be achieved with R4 condition (1000 rpm and $40 \mathrm{~mm} / \mathrm{min}$ ) while the reduced speed of $600 \mathrm{rpm}$ incomplete formation can be seen. Further with medium speed and reduced feed, defects like porosity and mild burnishing could be seen.

The imperfections in the welded specimens are presented with the help of cross-sectional optical macrocharacterization at $20 \mathrm{X}$ magnification. The macrophotographs showed the complete nugget zone, retreating side, and the advancing side of the AA7075 and AA6061 
TABLE 4: Weld appearance during dissimilar FSW without reinforcement.

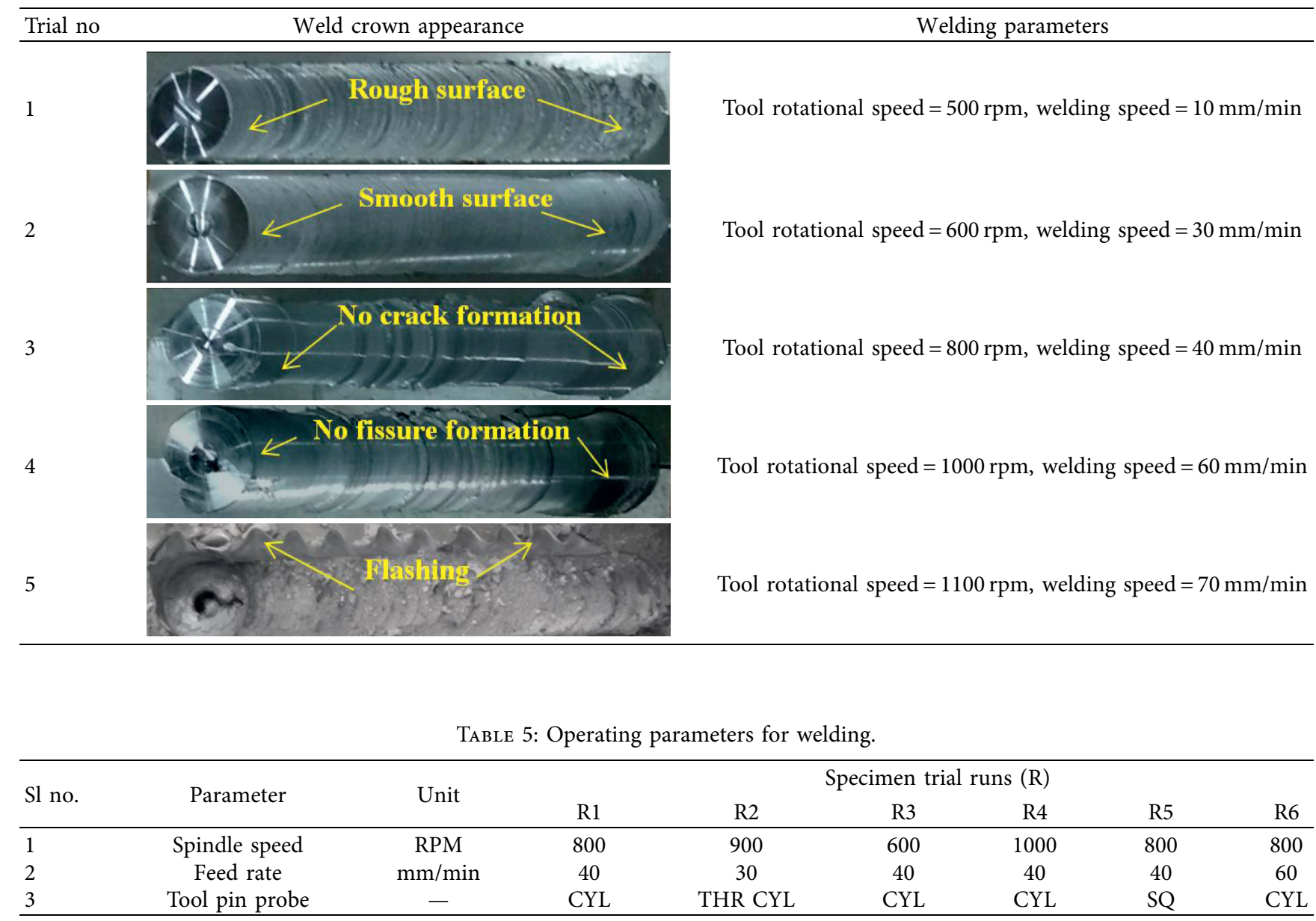

CYL: cylindrical pin profiled tool; THR CYL: threaded cylindrical pin profiled tool; SQ: square pin profiled tool.

aluminum alloy. It also revealed the complete fusion at the interface of the nugget zone on both sides. The observation on the macrograph is indicated in Table 6.

3.1. Microstructural Characterization. Figures $7(\mathrm{a})-7(\mathrm{~g})$ stages the microstructural location with optical microimages and FESEM images of parent alloys. The microstructural observation for dissimilar weld without reinforcement performed by cylindrical tool rotating at $800 \mathrm{rpm}$ and traversing speed at $40 \mathrm{~mm} / \mathrm{min}$ is represented in Figures 8(a) and $8(\mathrm{~b})$.

The microstructures of solution treated/precipitation hardened AA7075-T651 along the longitudinal section are showcased in Figure 7(b). The structure annihilates the primary aluminum phase with precipitates of $\mathrm{CuAl}_{2}, \mathrm{MgAl}_{2}$, and $\mathrm{Mg}_{2} \mathrm{Si}$ at $100 \mathrm{X}$ magnification.

Figure 7(c) divulges the AA6061-T6 microstructure observed in the longitudinal section. The microimage belongs to AA6061 alloy prepared in the longitudinal direction of the $6.35 \mathrm{~mm}$ plate. The microstructure shows elongated grains of fine $\alpha$-phase aluminum along the rolling/forming direction. The constituents of the micrograph are $\mathrm{Mg}_{2} \mathrm{Si}$ eutectic precipitates which are present uniformly in primary aluminum solid solution. The eutectic particles are of size 5 to 10 microns.

Figure 7 (d) shows the FESEM micrograph with EDS of AA7075-T651 alloy under magnification of 500X. The higher magnification has resolved the fine eutectic constituents along the grain boundaries of primary aluminum grains. EDS showed the presence of all the main eutectic constituent elements (C-0.1 wt. \%, O-1.31 wt.\%, Mg-2.59 wt.\%, Al-88.59 wt.\%, Cu-1.54 wt.\%, and Zn-5.96 wt.\%).

Figure 7(e) shows the FESEM micrograph with EDS of AA6061-T6 at a magnification of 500X. The higher magnification has resolved the fine precipitated eutectic $\mathrm{Mg}_{2} \mathrm{Si}$ particles in the matrix of primary aluminum solid solution. EDS showed the presence of C-0.12 wt. \%, O-1.18 wt.\%, Mg1.25 wt.\%, Al-94.31 wt.\%, and Cr-0.35 wt.\%.

Figure 8(a) shows the central portion of the nugget wherein the fusion of base alloys and precipitation of eutectics prevails. The left section (AA7075) pertains to imploded and recrystallized particles while the right portion highlights AA6061.

Figure 8(b) shows the FESEM $250 \mathrm{X}$ magnification micrograph from the nugget top zone containing fragmented particles of AA7075 and AA6061. The nugget grains are finer than parent metal and other zones. It is because the nugget 

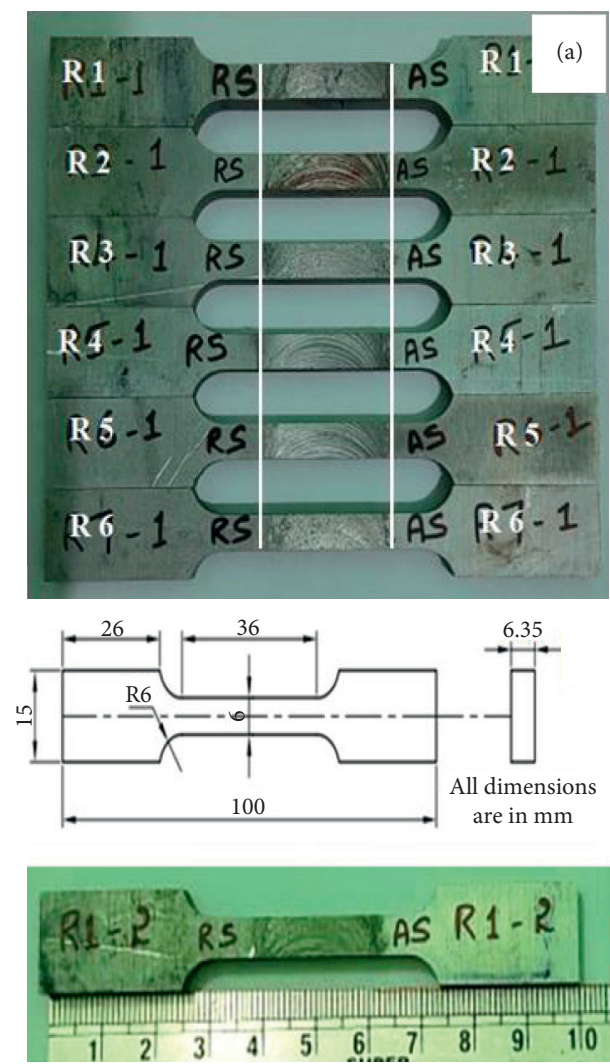

(c)
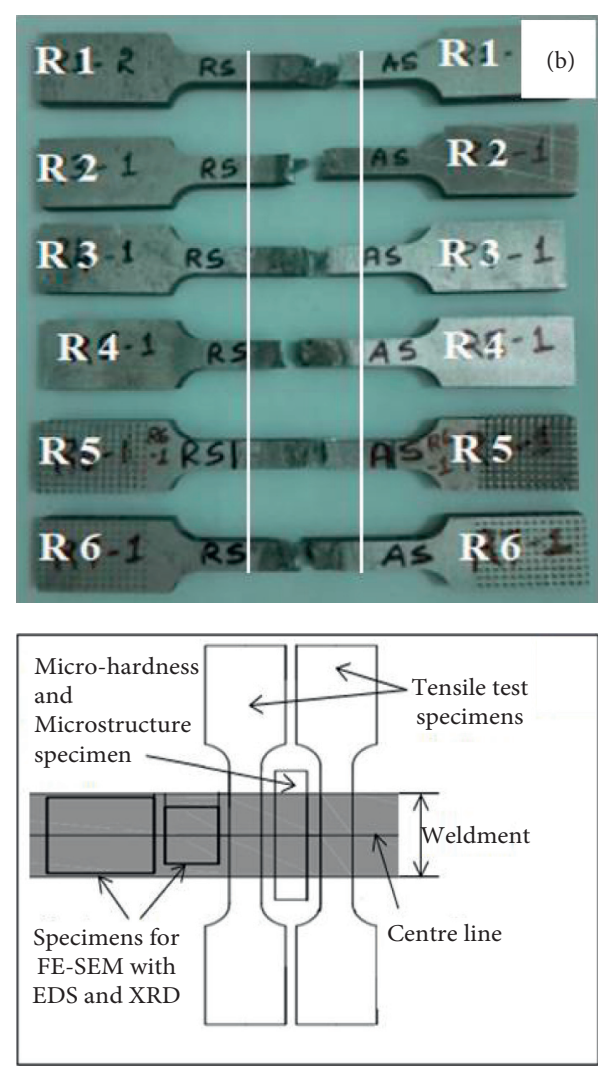

(d)

FIgURE 5: Tensile specimens: (a) before testing, (b) after testing, (c) schematic view of standard tensile specimen, and (d) representation of specimen extracted for various evaluations.

region metal matrix of AA7075 and AA6061 undergoes stirring at higher temperatures and gets fragmented due to the dynamic recrystallization effect. The material in the nugget zone is highly deformed/strained, with the material undergoing dynamic recrystallization due to associated heating.

The optical microstructural observations and FESEM micrographs for friction stir composite weld obtained with cylindrical tool running at $800 \mathrm{rpm}$ and $40 \mathrm{~mm} / \mathrm{min}$ feed rate are presented in Figures 9(a)-9(c) and 10(a)-10(c).

RS-interface shows the interface fusion zone of AA7075 and the nugget. The right portion shows RS AA7075 and the nugget zone on the left. The grains are fragmented at the nugget zone owing to dynamic recrystallization. The precipitated grains are bigger in size and elongated along the direction of the tool. The fusion zone possibly has deposited h-BN particles as they appear dark. The dark thick streak could be a flow of h-BN particles along the interface.

The nugget top region shows the fragmented constituents of AA7075 and AA6061 and composite particles of $\mathrm{h}-\mathrm{BN}$. The nugget bottom region shows the grain orientation of the nugget zone due to tool stirring action. The dark particles could be additive h-BN and grain flow is along the upward direction. AS-Interface shows the interface zone of the advancing side with nugget at right and AA6061 at the left side of the micrograph. It is on the advancing side of the FSW process, and the fusion is uniform along the interface.
The heat of the process affected recrystallization, and particles appear bigger in size.

Figure 10(a) indicates the interfacial region of the parent and the nugget. The constituents of the two base metals are fragmented, and the fusion line is observed between the base metal at the left and the nugget zone at the right. Dispersion of h-BN agglomerates is noticeable along the fusion line at 500X magnification [19].

Figure 10 (b)shows the center zone of the nugget of the FSW process. The constituents of the AA7075 and AA6061 have undergone fusion, and the presence of reinforced particles of h-BN also could be seen as fine white dispersion. The two base metals have formed alternate layers with dispersions of h-BN particles. The magnification at $1000 \mathrm{X}$ showed the grain deformation where the high plasticity of the metal is observed with the parameters used. Unlike the case of the interfacial zone, material in the nugget zone experiences agglomeration due to high strain without nucleation (subgrain formation), i.e., fragmentation of normal grains to subgrains (excessive dislocation concentration resulting in dislocation cells).

Figure 10 (c)was captured from the bottom of the nugget zone. The effect of frictional stress caused the fusion of the two base metal constituents with the dispersion of h-BN particles. The magnification at $800 \mathrm{X}$ showed the grain flow along the direction of revolution of the FSW tool where 


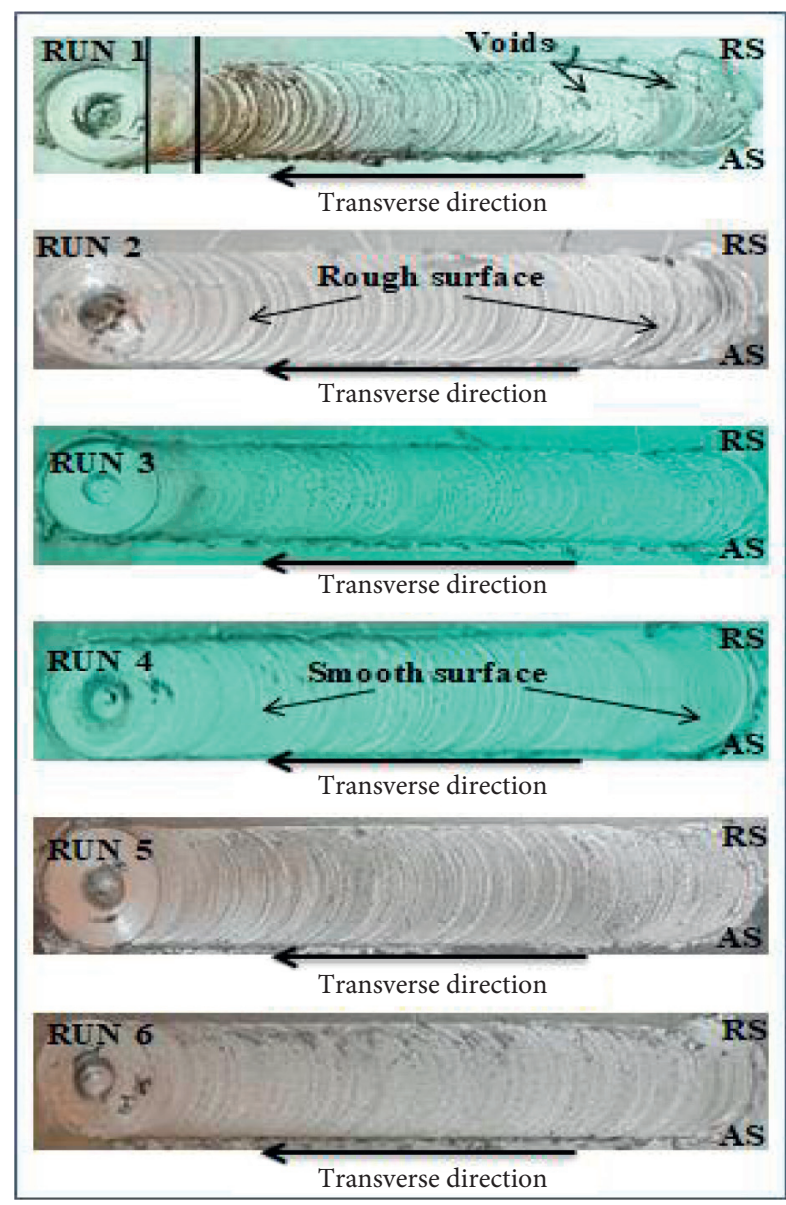

FIGURE 6: Visual representation of welded composite specimens.

h-BN nanoparticle dispersion is homogenous over the weld nugget zone owing to the double-pass FSW.

Figure 10(d) shows the EDS graph taken from the nugget zone, and the spectrum shows the detected elements at the nugget. The spectrum indicates the dispersed nanoparticles of $\mathrm{h}-\mathrm{BN}$ in the nugget zone. The presence of zinc and magnesium shows the fusion of the nugget with the constituents of AA7075 and AA6061 along with the h-BN as these elements were detected in the nugget zone. Table 7 represents the chemical composition rooted in the EDS observation.

The FESEM micrographs of stir welded composite specimen operated with threaded cylindrical tool running at $900 \mathrm{rpm}$ and $30 \mathrm{~mm} / \mathrm{min}$ feed rate are displayed in Figures 11(a)-11(d).

Figure 11(a) shows the interface zone of the parent metal and the nugget zone. The constituents of two base metals are fragmented, and the fusion line is observed between the base metal at the left and the nugget zone at the right. Some particles of $\mathrm{h}-\mathrm{BN}$ dispersed along the fusion line. The magnification is 200X. The FSW parameters probably caused the cavity along the fusion line. The combination of rotational speed $900 \mathrm{rpm}$ and feed rate $30 \mathrm{~mm} / \mathrm{min}$ resulted in the formation of the flow band along the fusion line of the weld [20]. In the case of cylindrical geometry, the threshold force can encounter discrete stick slip with incomplete stirring and generation of discrete pores/vacant sites.
Figure 11(b) shows the bottom line of the FSW zone, and the micrograph shows the presence of white particles along the grain boundaries which appear to be by the deposit of the $\mathrm{h}$-BN particles sprayed along the groove. The magnification is $800 \mathrm{X}$. As the matrix is from the nugget zone, the constituents of the two base metals are finely fragmented along with the reinforced particles. The region showcased rich distribution of h-BN particles in the matrix [13].

Figure 11(c) shows another field at the center of the FSW zone, and the micrograph shows the presence of uniformly dispersed white particles which appear to be by the spray of the h-BN particles along the groove. The particles could be resolved due to high magnification, 50,000X, of the field as their sizes are at the order of nano. The presence of some fine pores was also observed.

Figure 11(d) exhibits the micrograph captured at the interface zone of the AA6061 parent metal and the nugget zone. The left portion shows the nugget zone, and the right shows the parent metal microstructure with fine grain precipitated particles in AA6061 primary aluminum solid solution. The magnification is $500 \mathrm{X}$. The constituents of the nugget zone are finer than parent metal AA6061. The tendency toward the formation of the onion ring is initiated at the weld nugget zone attributable to the grain refinement and material mixing [13]. The presence of scattering particles in the rich region and onion rings could be attributable to relatively poor stirring.

The FESEM micrographs of an obtained composite specimen prepared with a square tool running at $800 \mathrm{rpm}$ and $40 \mathrm{~mm} / \mathrm{min}$ feed rate are represented in Figures 12(a) and $12(\mathrm{~b})$.

Figure 12(a) shows the center zone of the nugget of the FSW process. The constituents of AA7075 and AA6061 have undergone fusion, and the presence of reinforced particles of $\mathrm{h}-\mathrm{BN}$ also could be seen as fine white particle dispersion. The two base metals have formed alternate layers with dispersions of h-BN particles. $800 \mathrm{X}$ magnification revealed the dispersion of h-BN particles along the fusion line of the two base metal matrices.

Figure 12(b) shows the FESEM micrograph of the bottom line of the FSW zone, and the micrograph shows the presence of a lump of white particles which appear to be by the deposit of the h-BN particles sprayed along the groove. The particles could be resolved due to the high magnification of the field. The magnification is at 20,000X. As the h-BN particles' sizes are at the order of nano, the particles could be resolved at higher magnification. Clustering of reinforcement particles in the FSW bottom zone is attributable to ineffective stirring.

3.2. Grain Size Analysis. The grain size of the parent metal and composite specimens were measured in the weld nugget center at 2500X and 500X magnification using De-winter material plus 4.5 software according to ASTM E112 standard [21]. The average grain sizes obtained with operating tools are indicated in Figure 13.

The average grain size of the AA7075 and AA6061 base alloys is 50.86 and $65.6 \mu$, respectively. The grain size ranged from 10.8 to $13.14 \mu, 15.7$ to $21.34 \mu$, and 18.9 to $22.97 \mu$ for 
TABLe 6: Macrographs of the FSW composite welds.

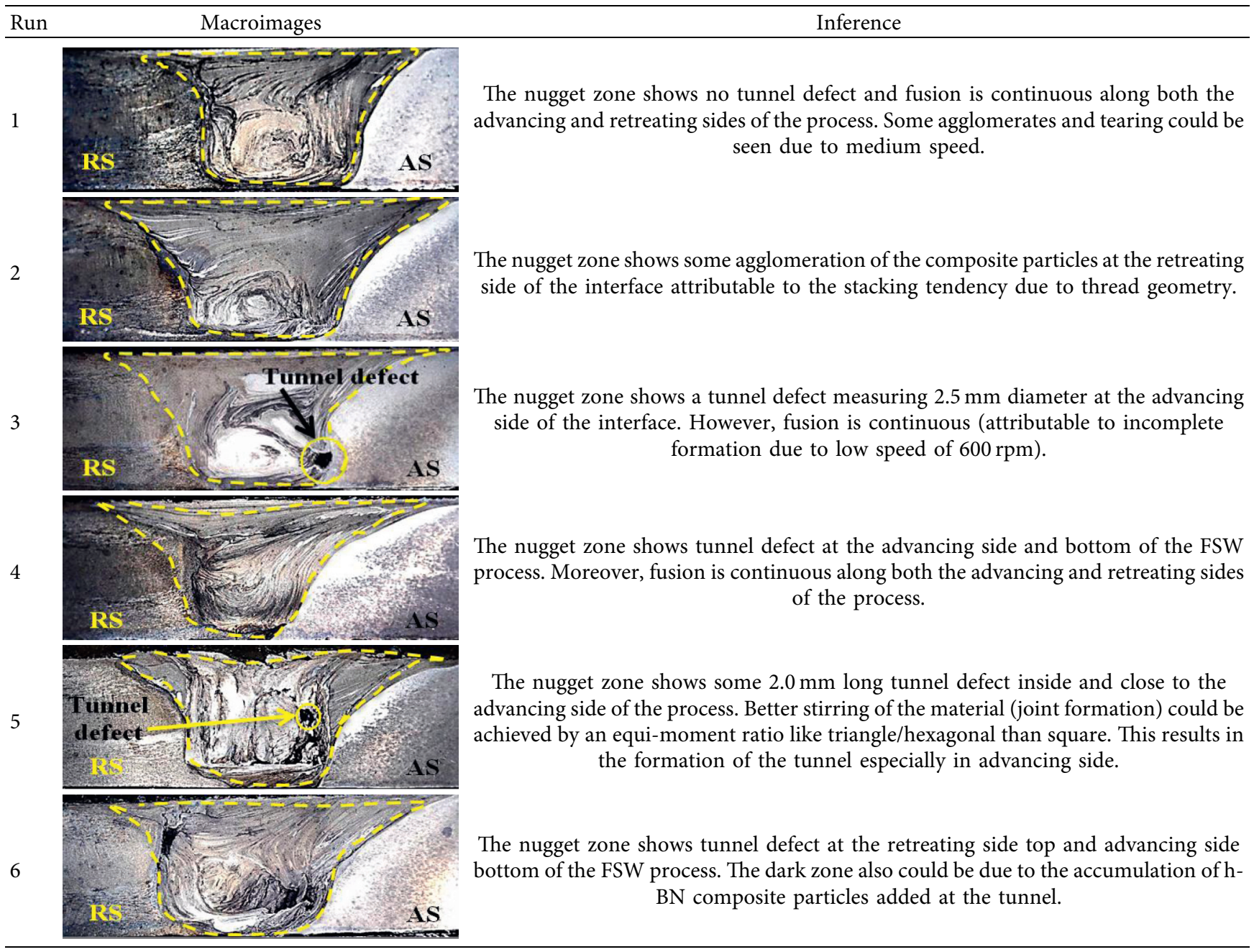

the composite weld operated with cylindrical, threaded cylindrical, and square tool, respectively.

The reinforced sample has significantly finer grains than the unreinforced sample. This could be attributable to the increased dislocation density due to applied strain restricting the grain growth progressing toward the nucleation of new grains. The reinforcement particles tend to create the pinning effect around the grain boundaries contributing to the enhanced grain refinement, and it is in agreement with the previous studies [10]. The cylindrical tool provides better heaving/distribution and mixing of reinforced matrix aiding in a reduction in grain size in contrast to other geometries. Effective stirring by cylindrical tool along with the presence of reinforcement $\mathrm{BN}$ particles can be effectively arrested (dislocation site generation) besides enhanced thermal inflow.

FSW involves higher-order plastic deformation of the material over the tool-work interface. Friction induces dynamic recrystallization of material. Plastic deformation of the material enhances the dislocation density which can lead to the generation of dislocation cell/subgrain formation. Besides, the presence of secondary phase particles such as reinforcements contributes to enhancing arresting mechanism leading to enhanced dislocation density. This facilitates further reduction in grain size due to the addition of reinforcements.

Figure 13 presents the significance of tool geometry on average grain size. It is seen that tool with cylindrical geometry facilitates nugget zone with finer grain attributable to the better stirring of material. The micrograph of the stir welded zone due to different tool pin geometries accounts for the observed variation in grain size. Unlike the case of fairly uniform microstructure, the presence of microstructure with voids and pooling of reinforcement results in relatively coarser grain. Such structures could be associated with nonuniform thermal influence and consequently mixed mode of grain.

3.3. XRD Analysis. X-ray diffraction (XRD) method describes the elemental spectrum analysis by revealing the various constituents present in the parent and stir welded composite specimen in the nugget region. Besides grain size evaluation, the nugget zone was characterized by elemental analysis. Typical XRD profiles for stir welding of AA7075 and AA6061 alloys with the cylindrical tool using spindle speed of $800 \mathrm{rpm}$ and $40 \mathrm{~mm} / \mathrm{min}$ tool traverse are presented 


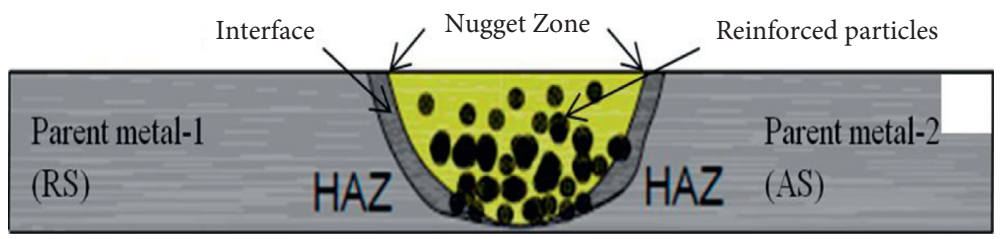

(a)
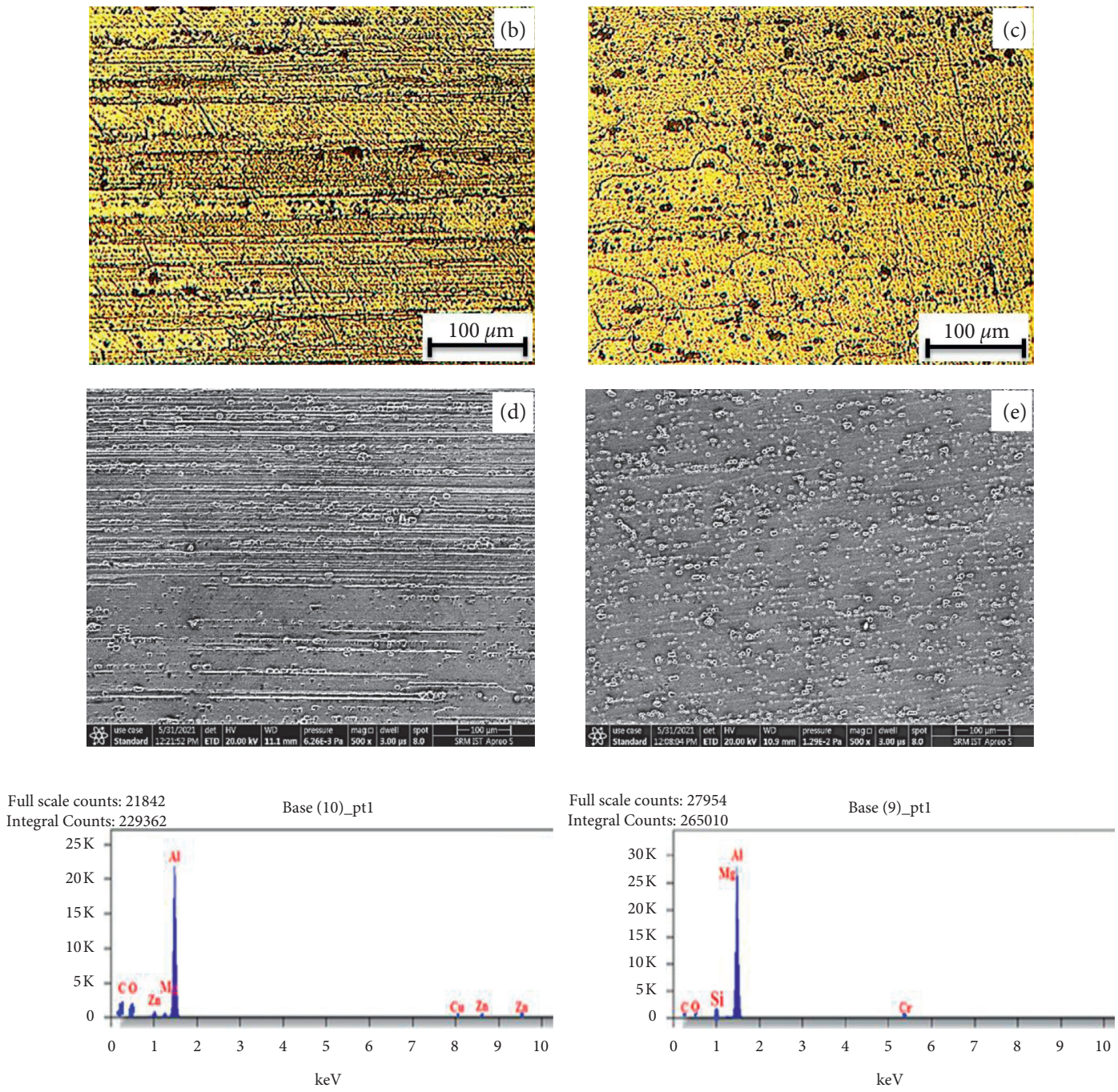

(f)

(g)

Figure 7: (a) Microstructural location, optical microimages of base alloys (b) AA7075-T651 and (c) AA6061-T6, FESEM micrographs of (d) AA7075-T651 and (e) AA6061-T6, and EDS of (f) AA7075-T651 and (g) AA6061-T6.

in the section. Figures 14(a)-14(c) reveal the XRD profiles of plain AA7075 and AA6061 alloys and weld at nugget zone with reinforcement.

Figure 14(a) identified the constituents of base metal AA7075 used in the FSW process. The base metal is in the solution treated and precipitation hardened condition. Hence, the XRD identified the primary aluminum phase, the eutectic constituents, and insoluble intermetallic constituents. The peaks of the graph identified the dominant constituents of
AA7075. Figure 14(b) indicates the primary aluminum phase and the precipitated eutectic constituent phase of $\mathrm{Mg}_{2} \mathrm{Si}$.

Figure 14(c) identified the presence of primary aluminum and eutectic constituents of both AA6061 and AA7075. The presence of $\mathrm{Mg}_{2} \mathrm{Si}$ from AA6061 and eutectics of $\mathrm{MgZn}_{2}$ and $\mathrm{Al}_{7} \mathrm{Cu}_{2} \mathrm{Mn}$ from AA 7071 is observed. This has established the fusion of AA6061 and AA7075 in the FSW region. The clear presence of $\mathrm{BN}$ indicates the metal matrix composite formation by AA6061 and AA7075. As h-BN is nano in size and as their 

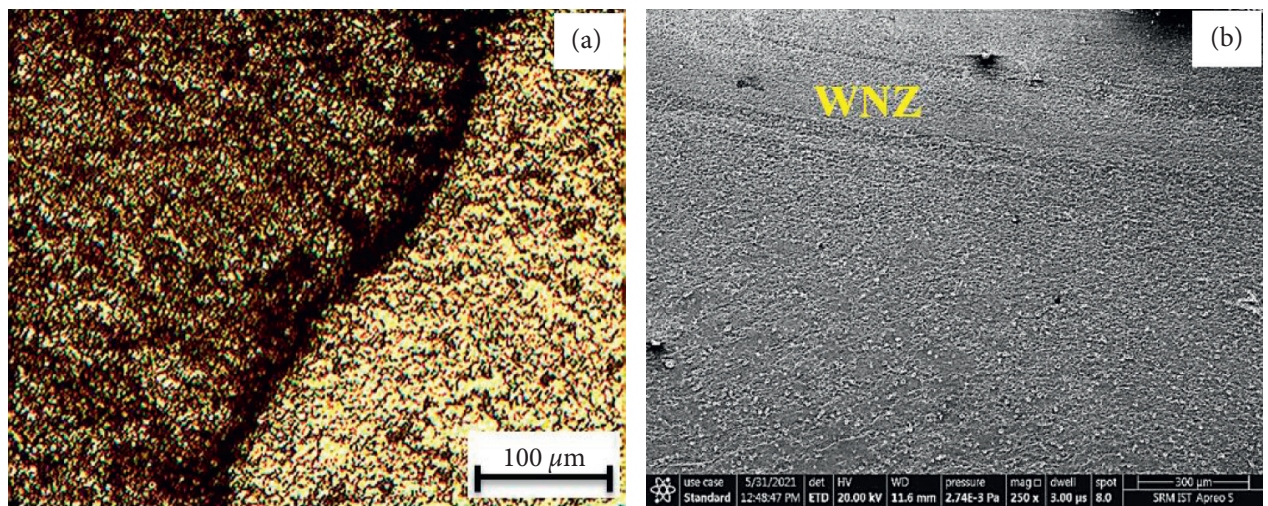

FIgURE 8: (a) Optical microimage of nugget center region. (b) FESEM micrograph of nugget top region.
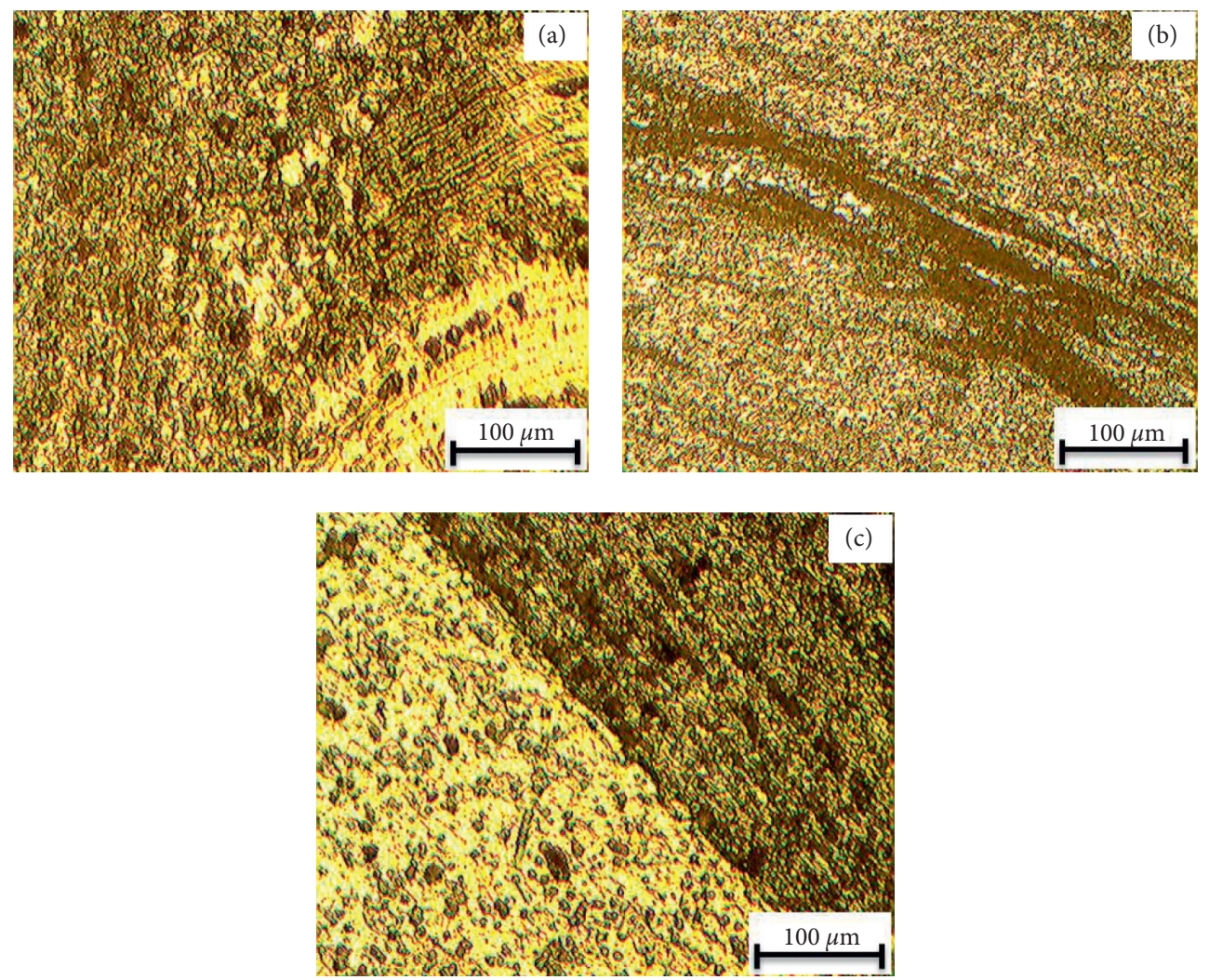

FIgURE 9: Optical micrographs of (a) RS-interface, (b) nugget top, and (c) AS-interface regions.

presence compared to the area is less, the intensity of count is lower. However, the stirring effect supplements adequate heat in a shorter duration furthering strong bonding of h-BN particles with alpha primary aluminum phase. Also, mild line broadening of aluminum peaks can be attributable to weld strain.

3.4. Evaluation of Tensile Strength. Friction stir welding is a standardized joining process involving the plasticization of the base material under the impact of the tool rotation at the desired speed and varied geometries. The response of the test specimen to FSW is evaluated in terms of joint quality by way of tensile strength, yield strength, and joint efficiency presented in Figures 15(a)-15(c).
Referring to Figure 15(a), it is seen that among the trial runs, run with the cylindrical tool and parameter $800 \mathrm{rpm}$ speed and traverse speed $40 \mathrm{~mm} / \mathrm{min}$ yields the best possible results. Relatively homogenous fine grain structure with the cylindrical tool compared to those of threaded/square geometry results in the observed enhanced strength. Also, the addition of reinforcement facilitates the further enhancement of tensile strength.

Figure 15(a) presents the significance of the stir welding parameter and reinforcement on the ultimate strength. It is seen that all the specimens exhibit enhanced ultimate strength with reinforcement. This is attributable to an effective arresting mechanism due to the presence of reinforcement in the material. Referring to the tool geometries, 

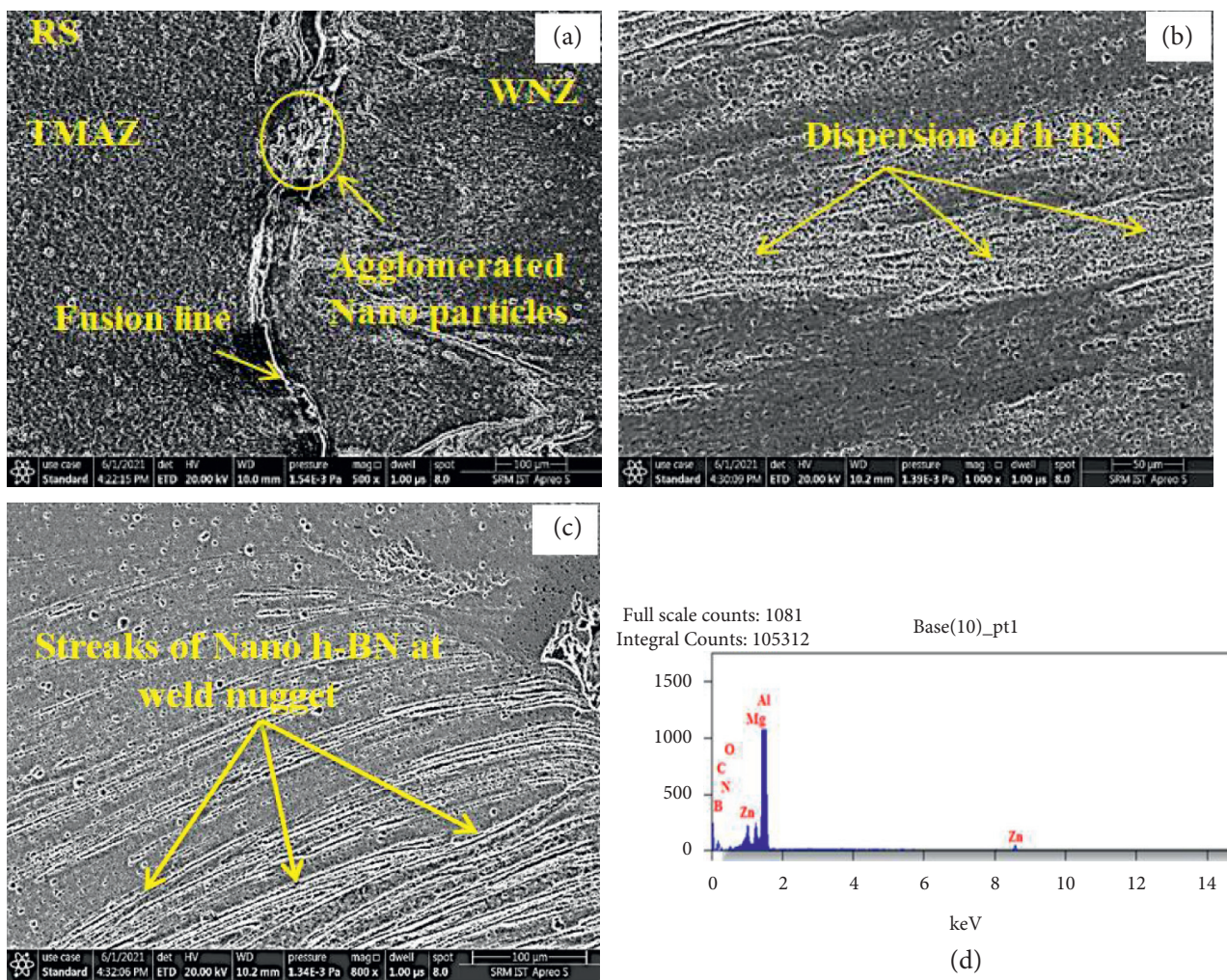

(d)

FIGURE 10: FESEM graphs of (a) interface zone, (b) nugget center, (c) nugget bottom, and (d) EDS graph.

TABLE 7: EDS-based chemical composition.

\begin{tabular}{lc}
\hline Element & Weight \% \\
\hline $\mathrm{B}$ & 2.01 \\
$\mathrm{C}$ & 0.25 \\
$\mathrm{~N}$ & 2.49 \\
$\mathrm{O}$ & 1.88 \\
$\mathrm{Mg}$ & 1.69 \\
$\mathrm{Al}$ & 88.68 \\
$\mathrm{Zn}$ & 3.00 \\
\hline
\end{tabular}

cylindrical geometry outperforms the square pin geometry (at $800 \mathrm{rpm}$ and $40 \mathrm{~mm} / \mathrm{min}$ ). This is attributable to the better stirring of the material with cylindrical tool besides agglomeration of reinforcement in the structure with stirring by square tool geometry.

Besides tool geometry, the process parameter tool speed and tool traverse affect the strength property. With a cylindrical tool, it is seen that, for a constant feed traverse, the tensile stress increases up to $800 \mathrm{rpm}$ followed by a small drop. With increasing stirring speed, the flow stress of the material over the nugget zone drops down facilitating better stirring and enhanced strength properties.

However, a threshold value of $800 \mathrm{rpm}$ for stir welding seems to realize low possible relaxation. With high temperature (at $1000 \mathrm{rpm}$ tool speed), the aluminum matrix would experience thermal softening besides reduced pinning effect by precipitation. This results in the observed reduction in strength.

The significance of tool traverse on the strength properties of friction stir welding can be seen with the illustration.
With a cylindrical tool, stirring at $800 \mathrm{rpm}$ results in varying strength. In the tool traverse $(40-60 \mathrm{~mm} / \mathrm{min})$, a reduction in the tensile strength is seen. Reduction in dwell time with an increase in the tool traverse will affect the stirring efficiency, thereby observing strength variation.

It can be inferred that tool geometry causing better friction stirring associated with optimal tool speed of $800 \mathrm{rpm}$ and $40 \mathrm{~mm} / \mathrm{min}$ yields the best possible results. Less effective stirring by threaded and square pin geometry leads to the observed reduction in the tensile strength. The illustration on the yield strength (Figure 15(b)) of similar trends of influence as in the case of ultimate stress is presented.

Imbibing of reinforcement particles in the matrix manifested marginal incremental variation in all the output responses of strength properties. Composite weld performed with the cylindrical tool running at $800 \mathrm{RPM}$ and $40 \mathrm{~mm} /$ min and feed exhibited enhanced strength compared to the other runs. Augmenting the number of passes results in the better mixing and distribution of nanoparticles into the metallic substrate [1]. The output responses tend to drop at $600 \mathrm{RPM}$ and $40 \mathrm{~mm} / \mathrm{min}$ due to insufficient material mixing and low temperature resulting in less heat generation at the tool-work interface. Solutionized and aged alloy response to relaxation and thermomechanical stressing induced by friction stir welding culminates in a reduction of strength properties [15].

An increase in the tool rotating speed also increases the stirring rate, thereby causing fine-grained microstructure owing to the improved strength property of the joint [2]. The 

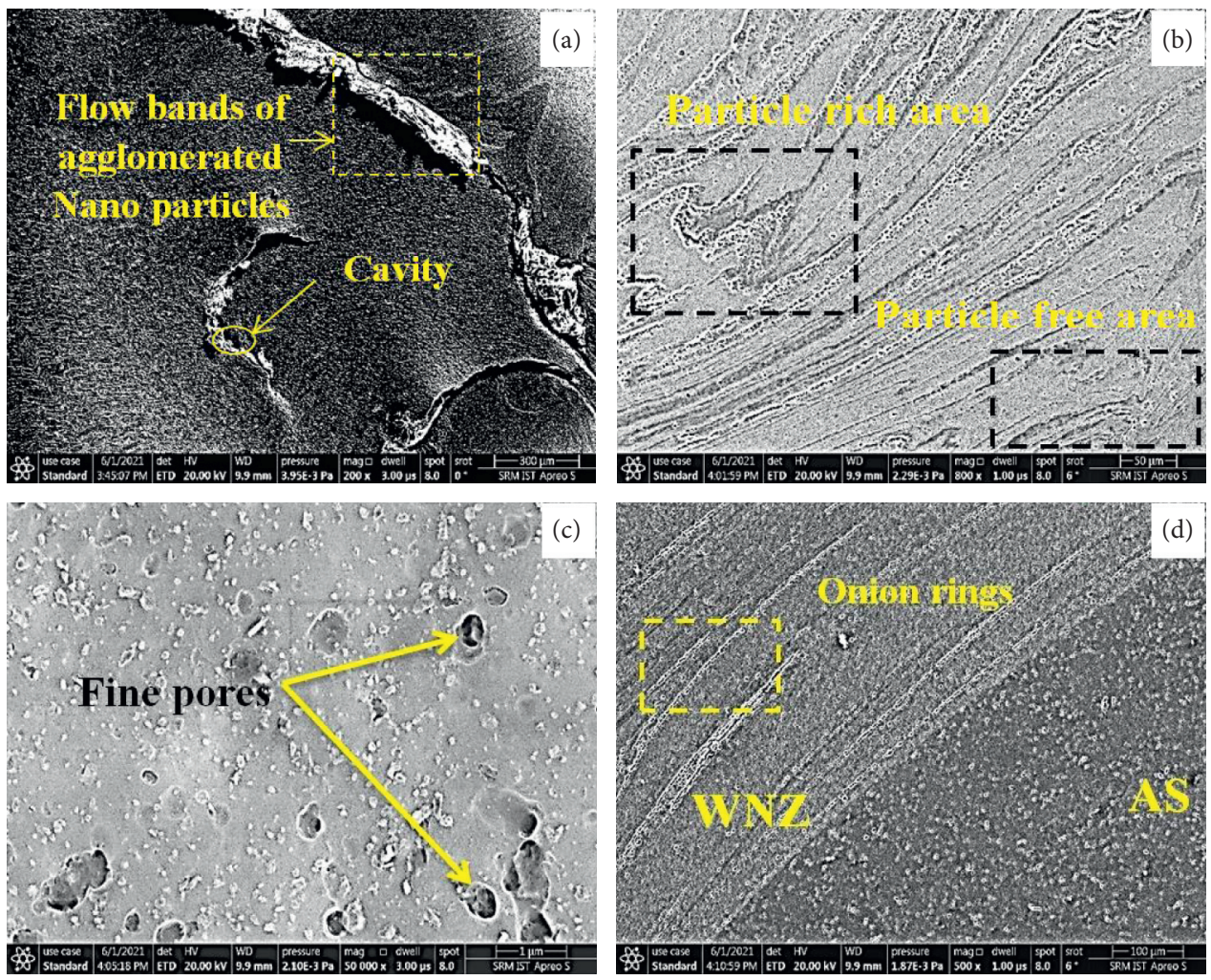

Figure 11: FESEM graphs of (a) interface zone-RS, (b) FSW bottom zone, (c) nugget center, and (d) interface zone-AS.
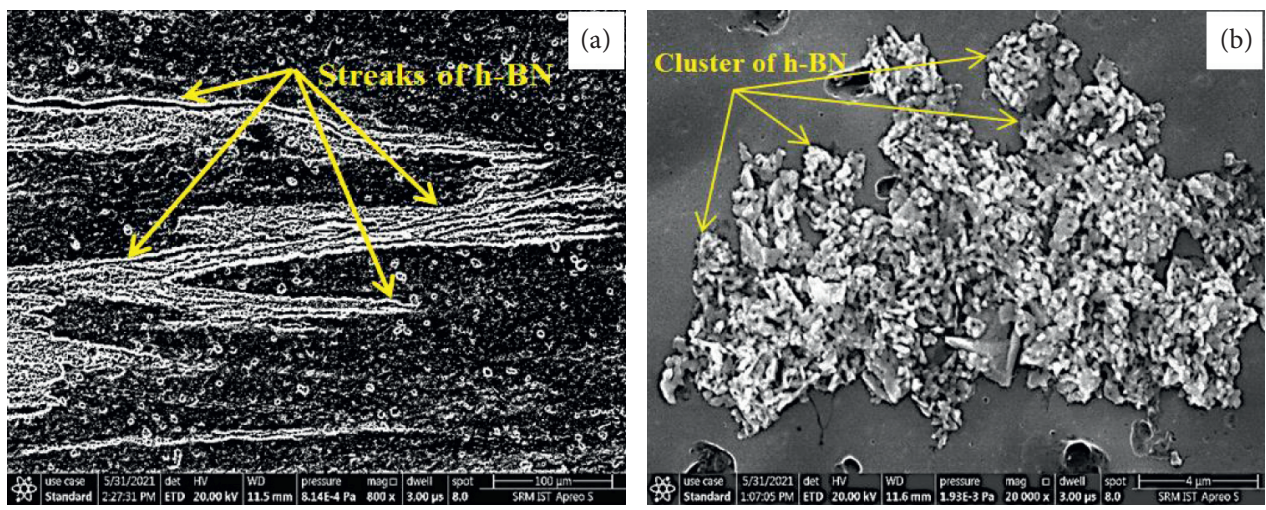

Figure 12: FESEM graphs of (a) nugget center and (b) FSW bottom zone.

rotating tool generates stirring action; thereby, homogenous refinement and distribution of reinforcement in the stir zone proceed, thus enhancing the tensile property of the alloys $[22,23]$.

FSW induces a dynamic recrystallization effect due to prolonged plastic deformation, and also, aluminum is a high stacking fault energy material $[24,25]$. The increase in strength with reinforcement as compared to unreinforced is ascribed to the fine dispersion of nanoscale ceramic specks in the aluminum matrix, substructure strengthening owing to grain refinement, and associated work hardening resulting from strain deviant between elastic reinforcement and plastic matrix [7, 8, 26, 27].
Around the tool pin probe, the frictional heat, as well as the stirring and mixing of the material, is initiated by the tool rotation. The relocation of the tool is prompted by the welding speed where the stirred material is pushed from the forefront to the rear end of the tool pin. When there is optimum stirring, adequate heat generation, and remotion of stirred material, the higher joint efficiency is ascribed to better unification of the material [9].

Low tensile strength is also attributable to the agglomeration of particles which in turn acted as the nucleation sites. The reinforcement reveals the noticeable effect on the grain refinement in the nugget region. $[12,28]$. Dislocation strengthening and grain refinement are the two major components 


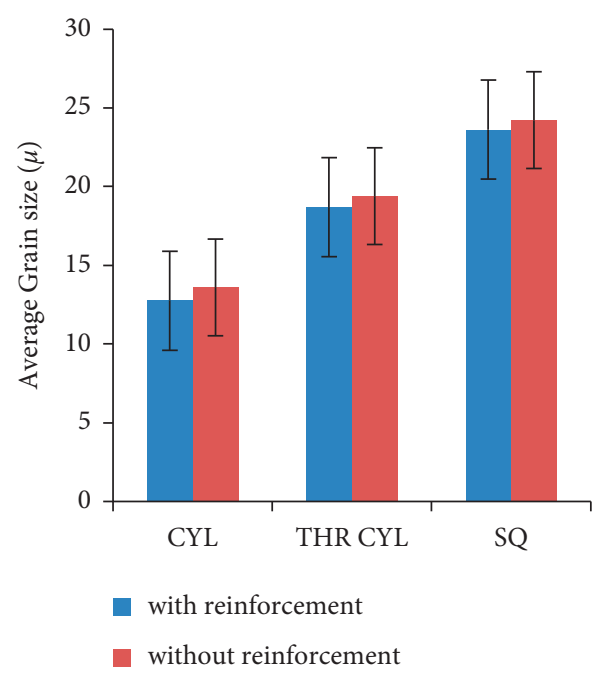

FIgURE 13: Grain size with operating tools.
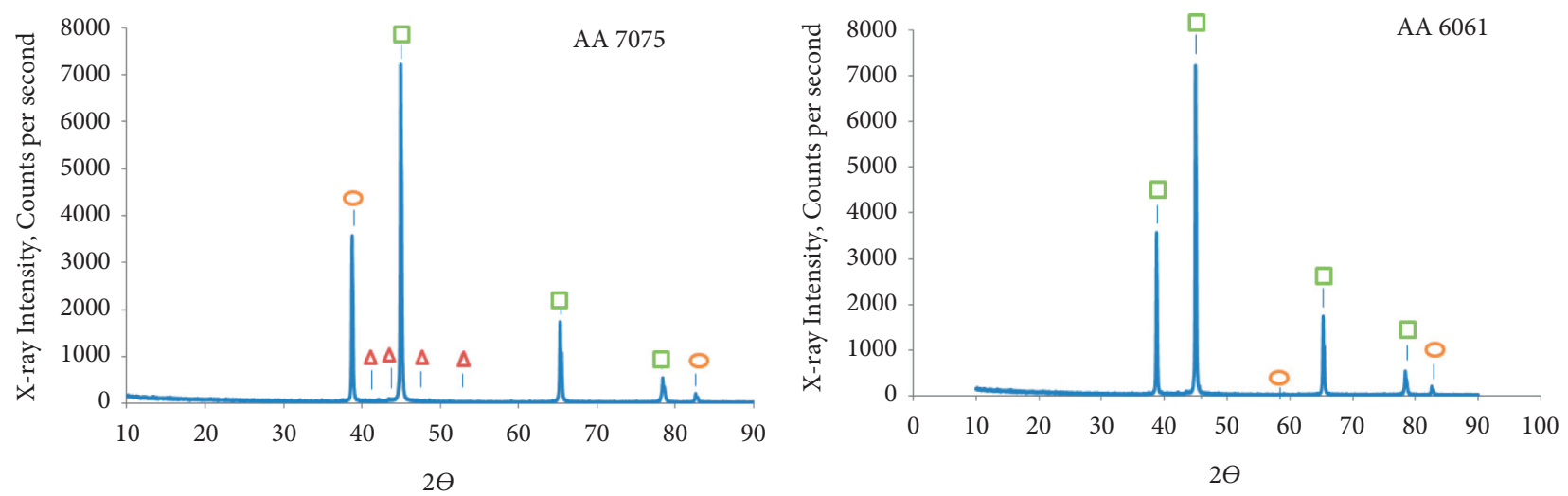
$\square \mathrm{A} 1$
$\triangle \mathrm{A} 1_{7}\left(\mathrm{Cu}_{2} \mathrm{Mn}\right)$
- $\mathrm{MgZn}_{2}$

$\square \mathrm{A} 1$

$\mathrm{Mg}_{2} \mathrm{Si}$

(a)

(b)

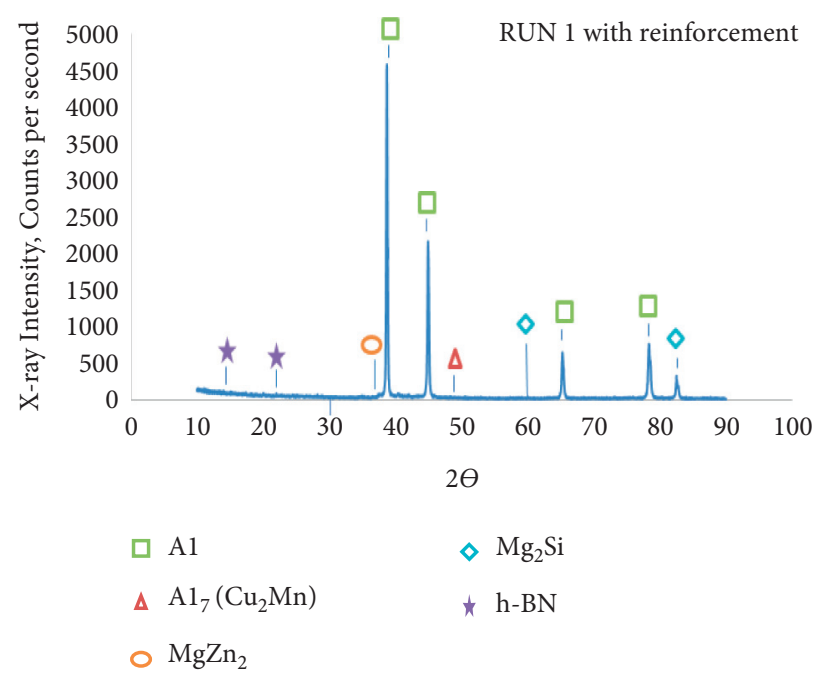

(c)

Figure 14: XRD spectrums of (a) AA7075 alloy, (b) AA6061 alloy, and (c) weld with reinforcement. 


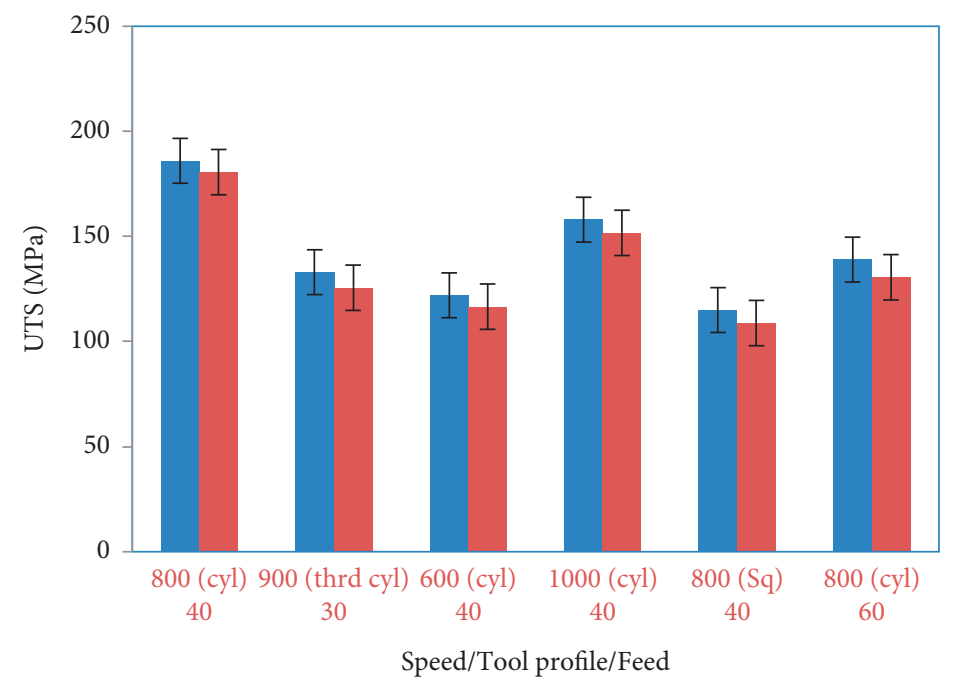

with reinforcement

- without reinforcement

(a)

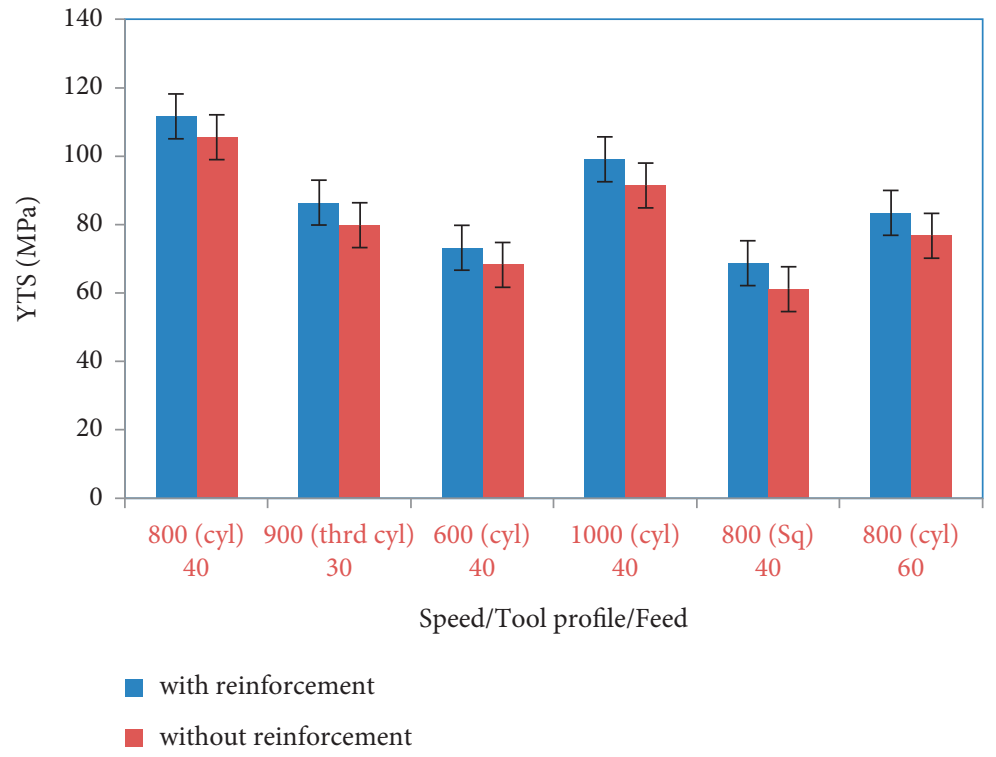

(b)

Figure 15: Continued. 


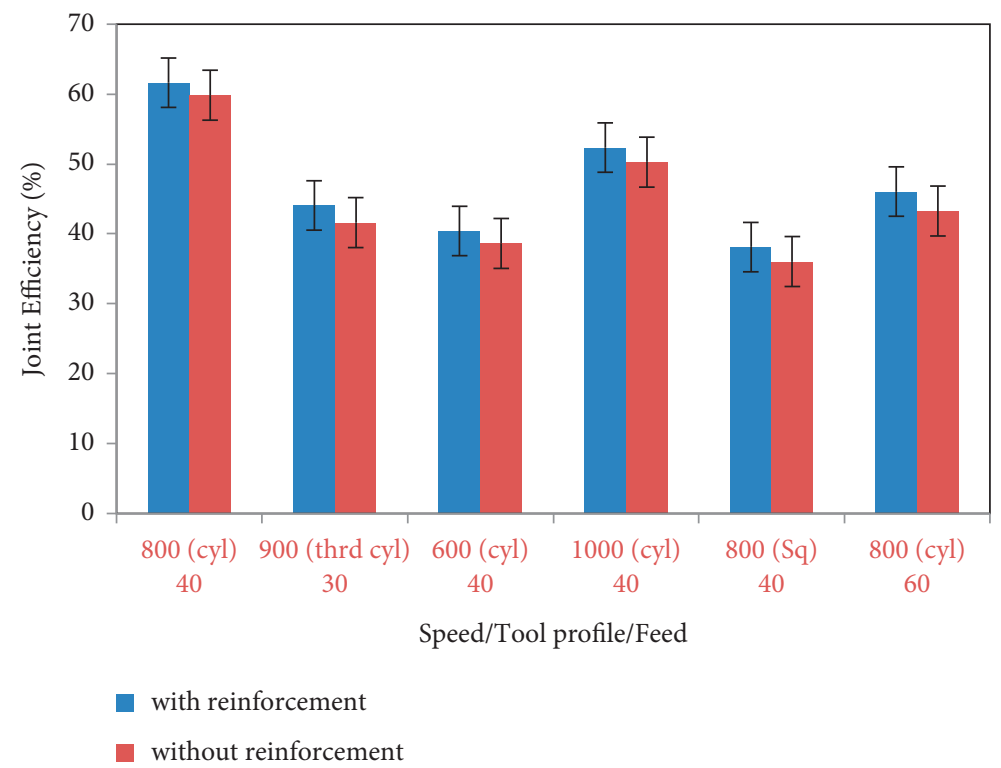

(c)

FIGURE 15: Process parameters effect on (a) UTS, (b) YTS, and (c) joint efficiency.
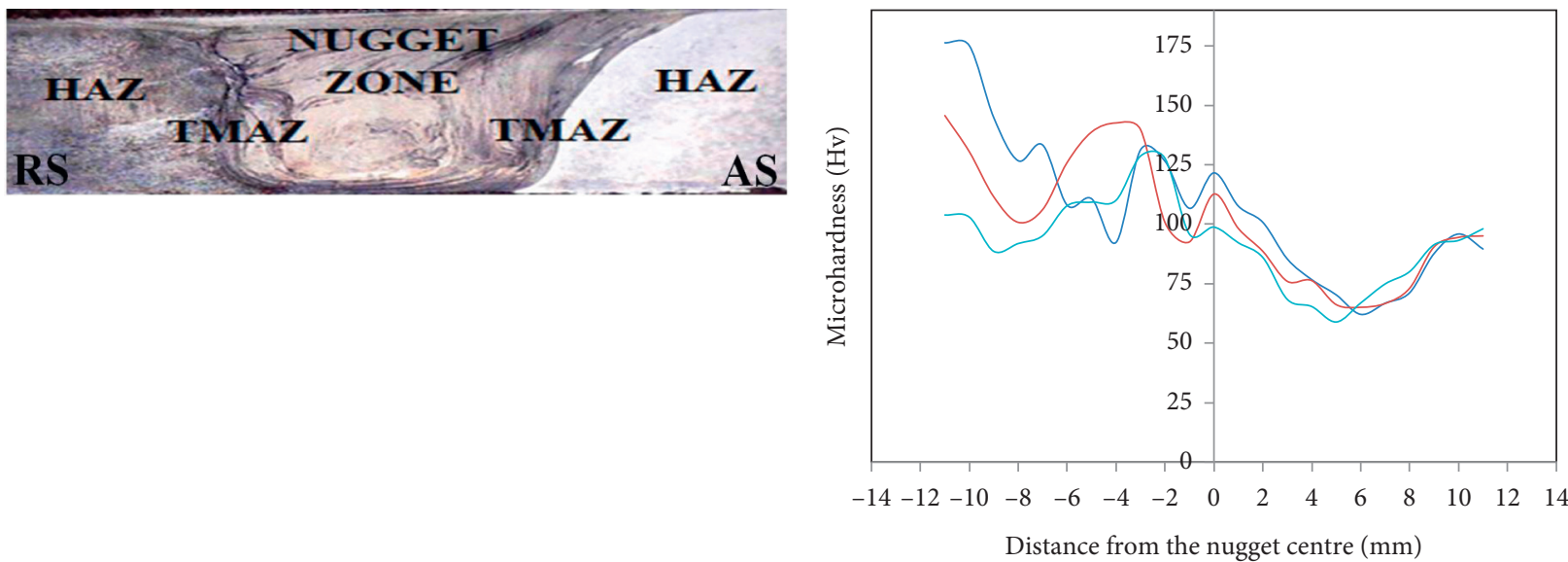

- R $1-\mathrm{R} 2-\mathrm{R} 5$

(a)

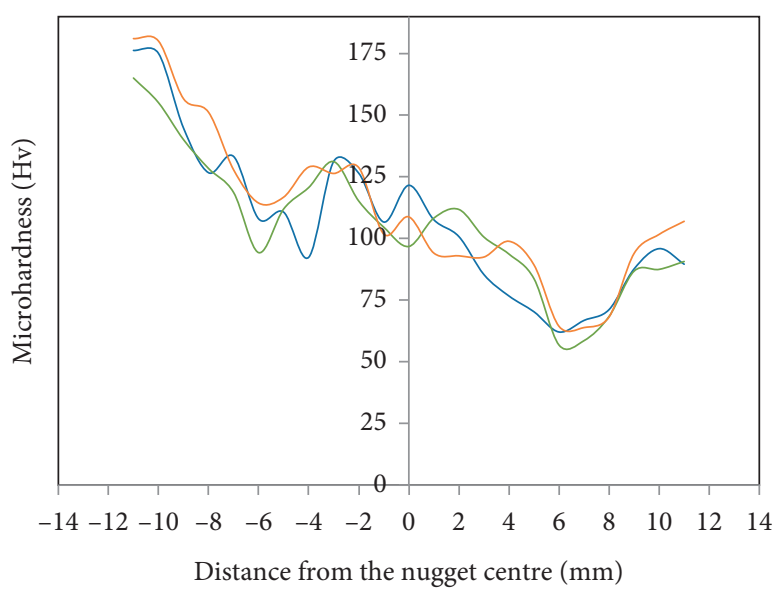

- R $1-\mathrm{R} 3-\mathrm{R} 6$ (b)

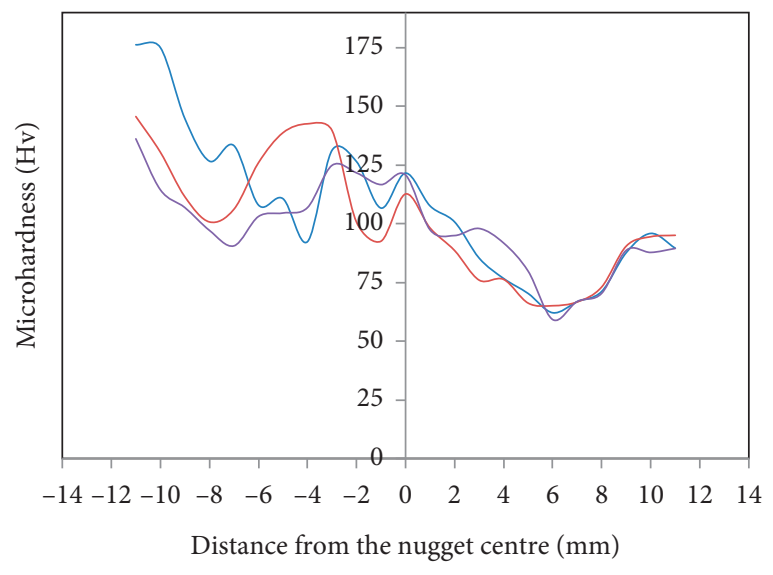

$-\mathrm{R} 1-\mathrm{R} 2-\mathrm{R} 4$

(c)

(d)

FIgURE 16: Continued. 

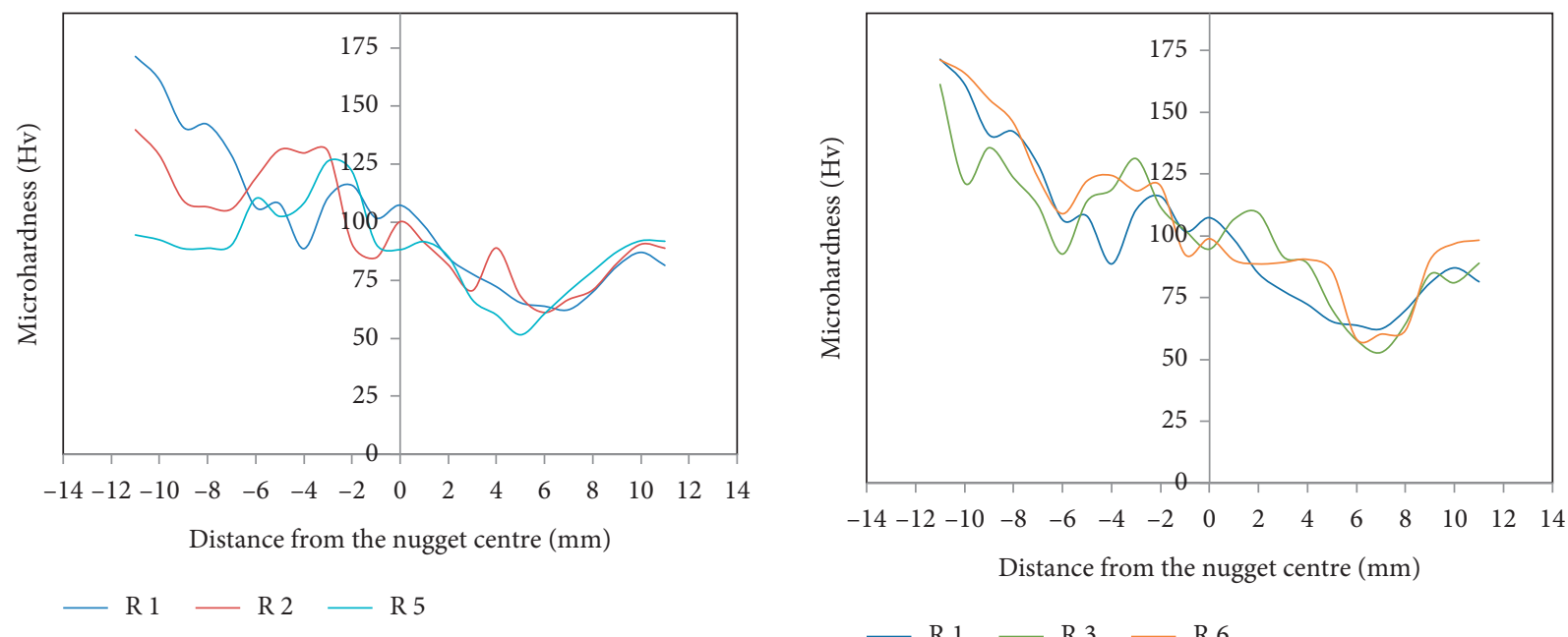

(e)

(f)

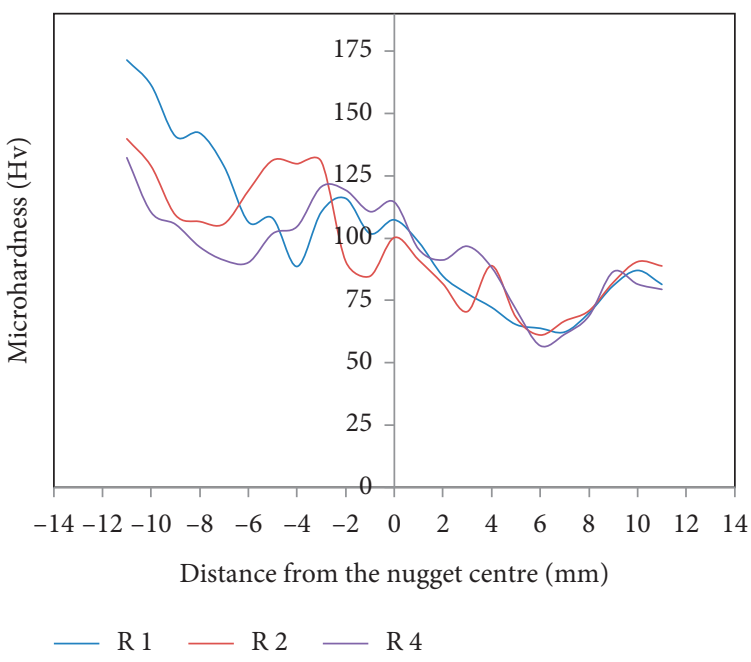

(g)

FIGURE 16: (a) Microhardness survey location and hardness survey of (b-d) composite welds and (e-g) welds without reinforcement.

which affect the mechanical properties of the nugget material. The secondary phase particles influence the grain boundaries and act as an obstacle to the dislocation's motion. The strengthening effect and grain structure distinction govern the enhancement of the tensile strength of the material [13].

3.5. Microhardness Survey. The efficacy of friction stir welding by the mode of grain refining and subsequent augmentation of strength depends on the selection of base alloy predominately ductile behavior and tool-work nature. The frictional heat generated ensuing strain strengthening and dynamic recrystallization consummates in improved weld structure properties [15]. This is proven in the observed variation of the hardness of the fabricated alloy with and without reinforcement.

Tool geometry, tool rotation, and feed rate have an impact on the microhardness variation of the fabricated material with and without composite particles. The microhardness survey was carried out at different locations from retreating to the advancing region of the weld. The hardness was measured at a depth of $1.5 \mathrm{~mm}$ beneath the FSW surface of the plate. The observed normal values for the base materials are $109.56 \mathrm{Hv}$ (AA6061-T6) and 178.32 Hv (AA7075T651), respectively. The survey encompassed the zones of the weldment with and without reinforcement displayed in Figures 16(a)-16(g) which clearly present the influence on microhardness distribution across the welded zone.

The hardness values measured for the unreinforced weld trials across the nugget center line are 107.3, 100.2, 94.6, 114.4, 88.2, and 98.8 Hv. The nugget zones exhibiting the improved hardness values for the trials with reinforcement are 121.6, 112.7, 96.8, 120.8, 98.8, and 108.8Hv. In addition to the existence of fine eutectics in the primary aluminum matrix, hard $\mathrm{BN}$ resulted in a higher hardness value when compared to that of the weld without nanoparticles.

The enhanced hardness in aluminum matrix nanocomposites is ascribed to the phenomenal inherent features of the reinforcement particles and also the possible 
variable thermal gradient/coefficient between reinforcement and matrix phase caused by dislocation/displacement $[29,30]$.

The effect of the cylindrical tool influences the hardness compared to the conical profile [31]. It is observed that barring the cylindrical geometry, FSW carried out with the other two tools is nearly thermal/heat inflow rather than inducing straining phenomena resulting in the lower order of hardness at the stir zone [32].

HAZ showed a diminishing/declining trend in hardness owing to the precipitate coarsening aiding in the formation of the eutectic composition of $\mathrm{Mg}_{2} \mathrm{Si} / \mathrm{MgZn} \mathrm{n}_{2} / \mathrm{Al}_{7} \mathrm{Cu}_{2} \mathrm{Mn}$. The reduction in hardness is also imputed to the surface softening because there is no strain hardening effect. The hardness value shoots up at the TMAZ region and then approaches the parent alloy. Such findings are attributable to heat treatment of the alloy contributing to the homogenization effect [15].

\section{Conclusions}

The FSW emerged as a novel approach for the fabrication of surface composites with the enhancement of the grain structure in the weld zone directing toward microstructural modification. In this study, friction stir dissimilar welding with and without the inclusion of nanoceramic particles is investigated. The conclusions outlined are as follows:

(1) Three different tool pin probes are fabricated to carry out the double-pass FSW process in evaluating the mechanical and morphological studies of welded specimens with and without nanoreinforcement. Tool rotational speed of $800 \mathrm{rpm}$ and welding speed of $40 \mathrm{~mm} / \mathrm{min}$ are favorable to achieve firm weld.

(2) The yield and ultimate tensile strength increased with the addition of h-BN particles in the solutionized and artificially aged $\mathrm{Al}$ alloys.

(3) The presence of the nanoparticles in the weld zone increased the nucleation sites leading to the recrystallization mechanism. Double-pass FSW contributed to the homogenous distribution of particles.

(4) The h-BN nanoparticles proved their efficacious role in establishing grain refinement and microstructural characteristics of the stirred zone.

(5) It is evident that double-pass stir welded samples using the cylindrical tool with reinforcement exhibited more tensile stressing. Thereby, improved strength property is noticed in contrast to the unreinforced samples and other tool pin geometries.

(6) The ultragrain refinement as a consequence of FSW forms dynamic recrystallization as reflected in the size of grains. Double-pass FSW with h-BN reinforcement resulted in significant grain refinement with the formation of equiaxed grains. The presence of eutectic grains in the base alloys showcased improved/enhanced hardness in the nugget. The percentage enhancement in microhardness for the weldment ranged between $2.98 \%$ and $11.76 \%$.
(7) The concurrent improvement in strength property and hardness furthers the viability of using the FSW technique in the aerospace and automobile sectors.

\section{Data Availability}

The data used to support the findings of this study are included within the article.

\section{Disclosure}

The abstract of this study was already presented in the AIP Conference Proceedings 2020 [31].

\section{Conflicts of Interest}

The authors declare that there are no conflicts of interest regarding the publication of this study.

\section{References}

[1] D. A. Dragatogiannis, E. P. Koumoulos, I. A. Kartsonakis, D. I. Pantelis, P. N. Karakizis, and C. A. Charitidis, "Dissimilar friction stir welding between 5083 and $6082 \mathrm{Al}$ alloys reinforced with TiC nanoparticles," Materials and Manufacturing Processes, vol. 31, no. 16, pp. 2101-2114, 2015.

[2] A. M. Hassan, M. Almomani, T. Qasim, and A. Ghaithan, "Effect of processing parameters on friction stir welded aluminum matrix composites wear behavior," Materials and Manufacturing Processes, vol. 27, no. 12, pp. 1419-1423, 2012.

[3] A. R. Cisko, J. B. Jordon, R. L. Amaro et al., "A parametric investigation on friction stir welding of Al-Li 2099," Materials and Manufacturing Processes, vol. 35, no. 10, pp. 1069-1076, 2020.

[4] J. John, S. P. Shanmuganatan, M. B. Kiran, V. S. Senthil Kumar, and R. Krishnamurthy, "Friction stir processing combined with incremental forming effect on aa2014-T6," Materials and Manufacturing Processes, vol. 36, no. 8, pp. 950-966, 2021.

[5] A. Moharami, A. Razaghian, B. Babaei, O. Ojo, and M. Šlapáková, "Role of Mg2Si particles on mechanical, wear, and corrosion behaviors of friction stir welding of AA6061-T6 and $\mathrm{Al}-\mathrm{Mg}_{2} \mathrm{Si}$ composite," Journal of Composite Materials, vol. 54, no. 26, pp. 4035-4057, 2020.

[6] K. S. A. Ali, V. Mohanavel, S. A. Vendan et al., "Mechanical and microstructural characterization of friction stir welded $\mathrm{SiC}$ and B4C reinforced aluminium alloy AA6061 metal matrix composites," Materials, vol. 14, no. 11, p. 3110, 2021.

[7] A. Abdollahzadeh, A. Shokuhfar, J. M. Cabrera, A. P. Zhilyaev, and H. Omidvar, "In-situ nanocomposite in friction stir welding of 6061-T6 aluminum alloy to AZ31 magnesium alloy," Journal of Materials Processing Technology, vol. 263, pp. 296-307, 2019.

[8] M. Bahrami, M. Farahmand Nikoo, M. K. Besharati Givi, and K. Mohammad, "Microstructural and mechanical behaviors of nano-SiC-reinforced AA7075-O FSW joints prepared through two passes," Materials Science and Engineering A, vol. 626, pp. 220-228, 2015.

[9] I. Dinaharan and N. Murugan, "Effect of friction stir welding on microstructure, mechanical and wear properties of AA6061/ZrB2 in situ cast composites," Materials Science and Engineering A, vol. 543, pp. 257-266, 2012. 
[10] M. Tabasi, M. Farahani, M. K. B. Givi, M. Farzami, and A. Moharami, "Dissimilar friction stir welding of 7075 aluminum alloy to AZ31 magnesium alloy using SiC nanoparticles," International Journal of Advanced Manufacturing Technology, vol. 86, no. 1-4, pp. 705-715, 2015.

[11] A. Sadooghi and K. Rahmani, "Experimental study on mechanical and tribology behaviors of $\mathrm{Mg}-\mathrm{SiC}$ nano/micro composite produced by friction stir process," Journal of Mechanical Science and Technology, vol. 35, no. 3, pp. 11211127, 2021.

[12] M. Bodaghi and K. Dehghani, "Friction stir welding of AA5052: the effects of SiC nano-particles addition," International Journal of Advanced Manufacturing Technology, vol. 88, no. 9-12, pp. 2651-2660, 2016.

[13] T. Singh, S. Tiwari, and D. Shukla, "Effect of nano-sized particles on grain structure and mechanical behavior of friction stir welded Al-nanocomposites," Proceedings of the Institution of Mechanical Engineers-Part L: Journal of Materials: Design and Applications, vol. 234, no. 2, pp. 274-290, 2020.

[14] R. Pandiyarajan, P. Maran, N. Murugan, S. Marimuthu, and T. Sornakumar, "Friction stir welding of hybrid AA 6061$\mathrm{ZrO} 2-\mathrm{C}$ composites FSW process optimization using desirability approach," Materials Research Express, vol. 6, no. 6, Article ID 066553, 2019.

[15] J. John, S. P. Shanmuganatan, M. B. Kiran, V. S. Senthil Kumar, and R. Krishnamurthy, "Investigation of friction stir processing effect on AA 2014-T6," Materials and Manufacturing Processes, vol. 34, no. 2, pp. 159-176, 2019.

[16] S. RaviKumar, R. KajaBanthaNavas, and P. Sai Sujeeth, "Multiple response optimization studies for dissimilar friction stir welding parameters of 6061 to 7075 aluminium alloys," Materials Today: Proceedings, vol. 16, pp. 405-412, 2019.

[17] ASTM, ASTM 557-B Standard Test Methods for Tension Testing Wrought, Cast Aluminum and Magnesium Alloy Products, Vol. 2, ASTM, , West Conshohocken, PA, USA, 2007.

[18] Astm E3-11, Standard Guide For Preparation of Metallographic Specimens, ASTM, West Conshohocken, PA, USA, 2017.

[19] K. S. A. Kumar, S. M. Murigendrappa, H. Kumar, and H. Shekhar, "Effect of tool rotation speed on microstructure and tensile properties of FSW joints of 2024-t351 and 7075t651 reinforced with SiC nano particle: the role of FSW single pass," AIP Conference Proceedings, vol. 2018, Article ID 5029632, 2018.

[20] N. Parumandla and K. Adepu, "Effect of $\mathrm{Al}_{2} \mathrm{O}_{3}$ and $\mathrm{SiC}$ nano reinforcements on microstructure, mechanical and wear properties of surface nanocomposites fabricated by friction stir processing," Materials Science, vol. 24, no. 3, 2018.

[21] ASTM, Astm E 112 Standard Test Methods For Determining Average Grain Size, pp. 229-251, ASTM, West Conshohocken, PA, USA, 2021.

[22] V. K. Parikh, A. D. Badgujar, and N. D. Ghetiya, "Joining of metal matrix composites using friction stir welding: a review," Materials and Manufacturing Processes, vol. 34, no. 2, pp. 123-146, 2018.

[23] D. R. Ni, D. L. Chen, D. Wang, B. L. Xiao, and Z. Y. Ma, "Influence of microstructural evolution on tensile properties of friction stir welded joint of rolled SiCp/AA2009-T351 sheet," Materials \& Design, vol. 51, pp. 199-205, 2013.

[24] R. Bauri, D. Yadav, C. N. Shyam Kumar, and B. Balaji, "Tungsten particle reinforced Al 5083 composite with high strength and ductility," Materials Science and Engineering A, vol. 620, pp. 67-75, 2015.

[25] B. S. Yigezu, D. Venkateswarlu, M. M. Mahapatra, P. K. Jha, and N. R. Mandal, "On friction stir butt welding of $\mathrm{Al}+12 \mathrm{Si}$ / 10wt\%TiC in situ composite," Materials and Design, vol. 54, pp. 1019-1027, 2014.

[26] R. Palanivel, I. Dinaharan, R. F. Laubscher, and J. P. Davim, "Influence of boron nitride nanoparticles on microstructure and wear behavior of AA6082/TiB 2 hybrid aluminum composites synthesized by friction stir processing," Materials \& Design, vol. 106, pp. 195-204, 2016.

[27] T. Singh, S. K. Tiwari, and D. K. Shukla, "Novel method of nanoparticle addition for friction stir welding of aluminium alloy," Advances in Materials and Processing Technologies, vol. 2020, Article ID 1855397, 13 pages, 2020.

[28] M. Bahrami, K. Dehghani, and M. K. Besharati Givi, “A novel approach to develop aluminum matrix nano-composite employing friction stir welding technique," Materials \& Design, vol. 53, pp. 217-225, 2014.

[29] M. Navazani and K. Dehghani, "Fabrication of Mg-ZrO2 surface layer composites by friction stir processing," Journal of Materials Processing Technology, vol. 229, pp. 439-449, 2016.

[30] D. K. Sharma, V. Patel, V. Badheka, K. Mehta, and G. Upadhyay, "Fabrication of hybrid surface composites AA6061/(B4C + MoS2) via friction stir processing," Journal of Tribology, vol. 141, no. 5, 2019.

[31] M. Manjunath, S. U. Kurse, S. P. Shanmuganatan, and J. John, "Investigation of effect of process parameters on friction stir welded dissimilar AA6061 T6 and AA7075 T651," International Conference On Emerging Trends In Mechanical Engineering, vol. 2236, no. 1, pp. 1-20, 2020.

[32] K. Elangovan, V. Balasubramanian, and M. Valliappan, "Influences of tool pin profile and axial force on the formation of friction stir processing zone in AA6061 aluminium alloy," International Journal of Advanced Manufacturing Technology, vol. 38, no. 3-4, pp. 285-295, 2007. 